\title{
Possible roles of anti-type II collagen antibody and innate immunity in the development and progression of diabetic retinopathy
}

\author{
Tsunehiko Ikeda ${ }^{1,2} \cdot$ Kimitoshi Nakamura $^{3} \cdot$ Teruyo Kida $^{1} \cdot$ Hidehiro Oku ${ }^{1}$
}

Received: 27 February 2021 / Revised: 19 July 2021 / Accepted: 24 July 2021 / Published online: 11 August 2021

(c) The Author(s) 2021

\begin{abstract}
The pathogenesis of both diabetic retinopathy (DR) and rheumatoid arthritis (RA) has recently been considered to involve autoimmunity. Serum and synovial fluid levels of anti-type II collagen antibodies increase early after the onset of RA, thus inducing immune responses and subsequent hydrarthrosis and angiogenesis, which resemble diabetic macular edema and proliferative DR (PDR), respectively. We previously reported that DR is also associated with increased serum levels of antitype II collagen antibodies. Retinal hypoxia in DR may induce pericytes to express type II collagen, resulting in autoantibody production against type II collagen. As the result of blood-retinal barrier disruption, anti-type II collagen antibodies in the serum come into contact with type II collagen around the retinal vessels. A continued loss of pericytes and type II collagen around the retinal vessels may result in a shift of the immune reaction site from the retina to the vitreous. It has been reported that anti-inflammatory M2 macrophages increased in the vitreous of PDR patients, accompanied by the activation of the NOD-like receptor family pyrin domain-containing 3 (NLRP3) inflammasome, a key regulator of innate immunity. M2 macrophages promote angiogenesis and fibrosis, which might be exacerbated and prolonged by dysregulated innate immunity.
\end{abstract}

Keywords Diabetic retinopathy (DR) · Rheumatoid arthritis (RA) · Type II collagen · Autoimmunity · Innate immunity · NOD-like receptor family pyrin domain-containing 3 (NLRP3) · Pyroptosis · Efferocytosis · Specialized pro-resolving mediators (SPMs)

\section{Key messages}

- The loss of immunological tolerance leads to the production of anti-type II collagen antibodies, which are involved in the development and progression of diabetic retinopathy (DR).

- Hyperglycemia activates the innate immunity and prolongs each stage of DR.

- DR progresses through a process similar to that of wound healing, in which pro inflammatory M1 and antiinflammatory M2 macrophages are dominant in the early and late stages of the disease, respectively.

Tsunehiko Ikeda

tikeda@kaisei-hp.co.jp

1 Department of Ophthalmology, Osaka Medical and Pharmaceutical University, Takatsuki City, Osaka, Japan

2 Department of Ophthalmology, Osaka Kaisei Hospital, 1-6-10 Miyahara Yodogawa-ku, Osaka City, Osaka, Japan

3 Nakamura Eye Clinic, Matsumoto City, Nagano, Japan

\section{Introduction}

It is generally accepted that diabetic retinopathy (DR) is one of the chronic inflammatory diseases [1]. The clinical findings of DR include (1) increased blood levels of inflammatory biomarkers, such as C-reactive protein, fibrinogen, and neutrophil count [2-4]; (2) increased vitreous levels of inflammatory cytokines, such as interleukin (IL)-1 $\beta$, tumor 
necrosis factor-alpha (TNF- $\alpha$ ), and IL-6 [5, 6]; 3 ) infiltration of immune cells, such as macrophages, lymphocytes, and neutrophils, in the epiretinal and internal limiting membranes obtained during vitrectomy [7, 8]; (4) increased expressions of leukocyte adhesion molecules in the blood vessels of the retina and choroid [9]; (5) neutrophil entrapment in the retinal microcirculation [10]; (6) neutrophil infiltration in the choroidal capillaries [11]; and (7) activation of the renin-angiotensin system that enhances chronic inflammation [12]. These findings indicate that DR has a chronic inflammatory etiology. In addition to chronic inflammation, the involvement of autoimmunity in the etiology of DR has recently attracted considerable attention [13, 14]. It has been reported that HLA-DR and HLA-DQ antigens, types of HLA class II molecules, are related to the development and progression of DR $[15,16]$. The presence of autoantibodies in the serum of DR patients [14, 17-22] and the effectiveness of immunosuppressants, such as methotrexate, sirolimus (rapamycin), cyclosporin A, TNF- $\alpha$ inhibitors, and corticosteroids in treating diabetic macular edema (DME) [23-27], may also indicate the possibility that DR arises from autoimmunity.

In spite of poor glycemic control, diabetic patients who do not always develop DR after a long duration of the disease and patients with non-proliferative DR (NPDR) do not necessarily progress to proliferative diabetic retinopathy (PDR). Although many other factors, such as genetics, retinal ischemia and comorbidities, and myopia, may contribute to the onset and progression of DR, the individual differences may be due to the interplay of the various pathophysiological factors, including immune response.

We measured anti-type II collagen antibodies in the serum of DR patients and found that they were higher compared with the non-diabetic control group [20]. Based on the results of that study and a review of the previously published literature, we wish to herein discuss the likely role of immune response in the development of DR.

\section{Striking similarities between diabetic retinopathy and rheumatoid arthritis}

Rheumatoid arthritis (RA) is a typical disease with chronic inflammatory and autoimmune features [28]. The pathological conditions of RA are characterized by chronic inflammation of the joint associated with angiogenesis and fibroblast proliferation [29]. Similar to the vitreous body, type II collagen and hyaluronic acid are abundant in the articular cartilage and joint space, respectively [30]. Autoimmune reactions to type II collagen have been shown to be involved in the pathogenesis of RA [31,32], where Arthus reaction, a type of local type III hypersensitivity, occurs in the joint $[33,34]$, thus causing inflammation and destruction of the articular cartilage [28]. Persistent chronic inflammation of the joint causes hypoxia of synovial cells lining the inner surface of the joint capsule as well as angiogenesis induced by vascular endothelial growth factor (VEGF) and proliferation of synovial cells $[34,35]$. As a result, fibrovascular tissues called "pannus" are formed in the joint [36]. Similar findings to the advanced stage of RA are present in PDR patients, including retinal hypoxia, VEGF-induced angiogenesis, and proliferation of glial cells [37], resulting in the formation of proliferative membranes in the vitreous and vitreoretinal interface [38].

In this current review, we focused on the similarity of the anatomical structure and macromolecular composition between the vitreous body and the joint and the pathophysiological similarity between DR and RA (Fig. 1).

\section{Cartilage-affecting diseases and anti-type II collagen antibody}

The assumption that the autoimmune responses to type II collagen may be involved in the pathogenesis of RA is supported by increased serum and synovial fluid levels of antitype II collagen antibodies in the early stage of RA [32, 39] and by the observation that immunizing animals with type II collagen results in the formation of RA-like joint lesions [40, 41]. As type II collagen-containing tissues such as the articular cartilage and vitreous body are avascular, type II collagen is considered to be a sequestered antigen that can escape immune surveillance, resulting in immunological tolerance [42, 43]. Autoantibodies to type II collagen will be formed by the loss of immunological tolerance in RA patients, causing the progression of autoimmune-mediated joint destruction [43].

Increased serum levels of anti-type II collagen antibodies have been observed in other diseases affecting cartilaginous tissues of the joints (e.g., osteoarthritis, relapsing polychondritis, systemic lupus erythematosus, chronic gouty arthritis, and temporomandibular joint disturbance syndrome) [31, 44-47]. Besides serum anti-type II collagen antibodies and animal models using type II collagen immunization, the administration of a small amount of undenatured type II collagen reportedly induces oral immune tolerance to ameliorate the symptoms of RA, as described later in detail [48-50]. Altogether, this evidence suggests that anti-type II collagen antibodies might have a causative role as opposed to being a bystander of the diseases. Cartilaginous tissues are also present in the inner ear (and a part of auditory ossicles), and increased serum levels of anti-type II collagen antibodies have also been detected in the diseases affecting the inner ear, such as Meniere's disease, autoimmune ear disease (AIED), and otosclerosis [51-53]. The administration of type II collagen has been shown to cause Meniere's 


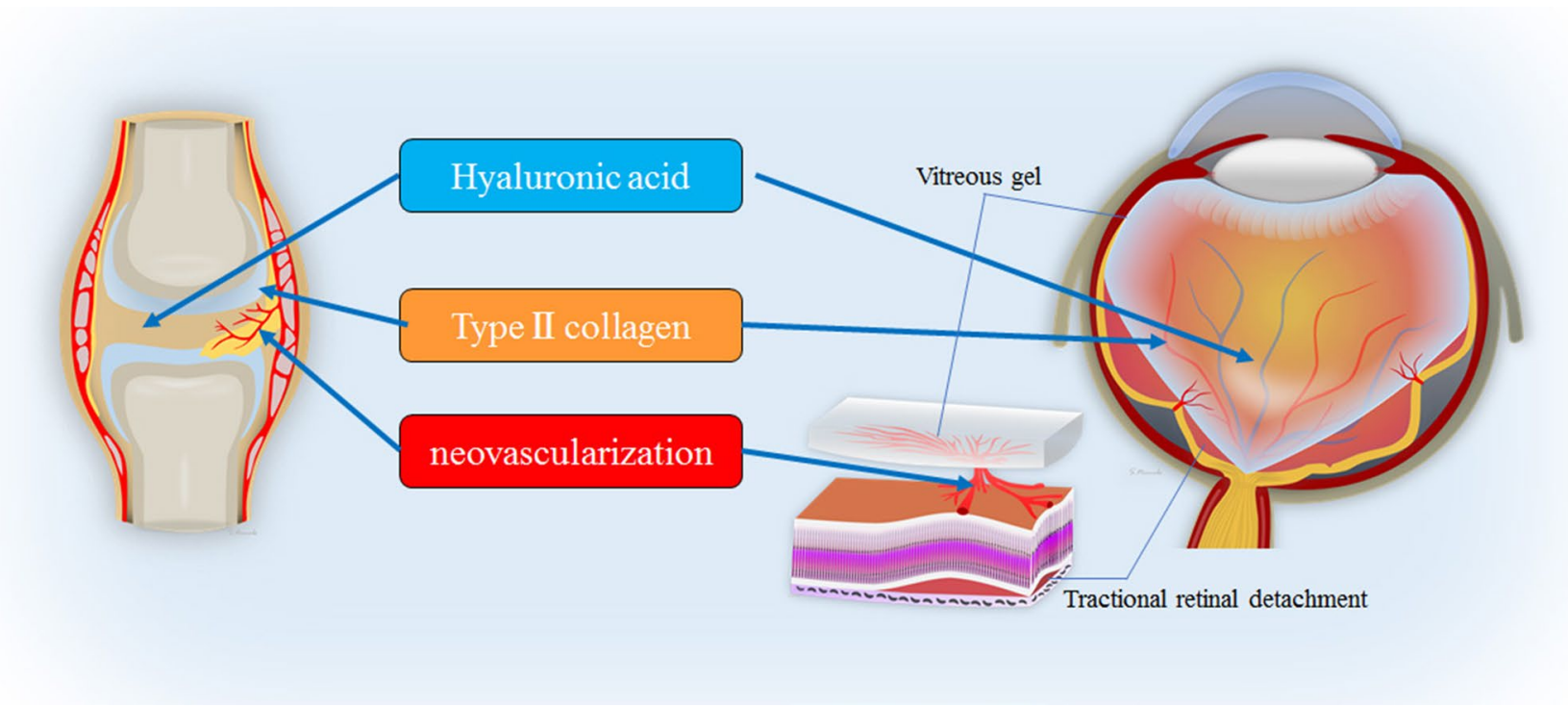

Fig. 1 Schematic images showing that anatomical structure and macromolecular composition of the joint and vitreous body. These images illustrate the pathophysiological similarity between the advanced stage of rheumatoid arthritis (RA) and proliferative diabetic retinopathy (PDR)

disease- and AIED-like conditions in animals [54, 55], thus raising the possibility that autoimmunity to type II collagen may be involved in the development of these diseases that affect the inner ear.

\section{Diabetic retinopathy and anti-type II collagen antibody}

Balashova et al. firstly reported that increased levels of antitype II collagen antibodies and immune complexes were observed in the serum and lacrimal fluid of DR patients [19]. We also measured the serum levels of anti-type II collagen antibodies in DR patients and found significantly higher levels of autoantibodies to type II collagen in DR patients compared to control subjects (Fig. 2) [20]. Remarkably, the serum levels of anti-type II collagen antibodies were higher in patients without DR than in patients with DR [20]. These results suggest that anti-type II collagen antibodies, which already increase in serum before the symptoms of DR are manifested, may be one of the factors involved in the onset of DR.

As mentioned above, the vitreous body, along with the joint and inner ear, is one of the few tissues that contain type II collagen, a component of cartilage. Since it has been considered that the autoimmunity to type II collagen is a causative factor in the pathogenesis of the cartilage-affecting diseases, such as RA and Meniere's disease, we assume that the similar mechanism may be involved in the development and progression of DR, a disease affecting the vitreous body in which type II collagen is abundantly present.
Although the mechanism by which the serum levels of anti-type II collagen antibodies increase in diabetic patients remains unclear, it has been shown that hypoxia and hyperglycemia caused blood-ocular barrier breakdown in those patients [56, 57], which may induce macrophages to migrate into the ocular tissues and to phagocytize type II collagen that is normally sequestered from the immune system. The peptide fragments of type II collagen presented by macrophages can be recognized by helper $\mathrm{T}$ cells, resulting in the production of anti-type II collagen antibodies by activated B cells [58]. Since activated microglia are capable of

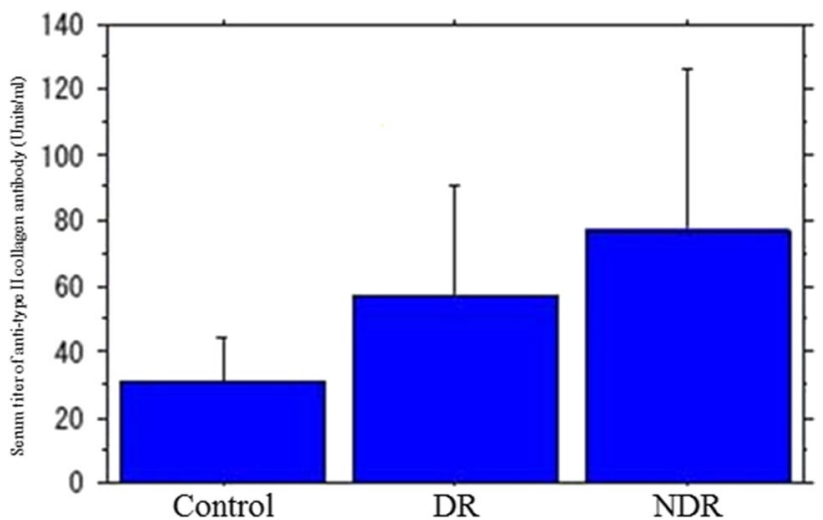

Fig. 2 This graph shows the serum levels of anti-type II collagen antibodies (units $/ \mathrm{ml}$ ) in diabetic retinopathy (DR) patients. The serum levels of anti-type II collagen antibodies in DR patients are significantly higher than those in control subjects. Notably, the levels are higher in the group of patients with non-diabetic DR than in the group of patients who already had DR 
phagocytosis and antigen presentation, the involvement of retinal microglia in anti-type II collagen antibody production is undeniable $[59,60]$.

\section{Proposal of an anti-type II collagen antibody-associated disease}

The vitreous body, joint, and inner ear, all of which contain type II collagen, are filled with liquid, namely the vitreous humor, synovial fluid, and endolymph, respectively. It is interesting to note that all of these tissues have also barrier mechanisms to the blood, i.e., the blood-ocular barrier, blood-joint barrier, and blood-labyrinth barrier, respectively [61-63], which separate type II collagen in these tissues from circulating immune cells. It seems likely that the disruption of these barriers results in the loss of immunological tolerance to type II collagen and the subsequent development of DME in DR, hydrarthrosis in RA, and endolymphatic hydrops in Meniere's disease [64, 65]. We have recently reported that the serum levels of anti-type II collagen IgG antibody were significantly higher in patients with epiretinal membrane than in control patients [66]. Consequently, chronic disorders affecting the vitreous body and cartilaginous tissues, including the above three diseases, are supposed to be in the same spectrum of immune tolerance breakdown to type II collagen, causing anti-type II collagen antibody production.

\section{Immunological divergence between diabetic retinopathy and rheumatoid arthritis}

Despite the speculated involvement of immune responses to type II collagen in the pathogenesis of both DR and RA, it seems rather uncommon that these two diseases develop simultaneously. In fact, it was previously reported that patients with RA were less predisposed to develop DR [67]. A number of studies have indicated the frequency of HLA-DR and -DQ antigens that were associated with disease susceptibility were different between DR and RA patients $[15,16,68]$. For example, HLA-DRB $1 * 0401$ and *0405 alleles are reportedly strongly associated with RA susceptibility [69-72], while these single alleles are nonsusceptible to DR. Conversely, it has been shown that the HLA-DRB $1 * 0402$ allele was associated with resistance to developing RA [73, 74], although a strong positive correlation between B $1 * 0402$ and DR susceptibility were reported [75].

A possible explanation for that finding is that there may be structural differences of collagen molecules recognized by lymphocytes between these two diseases. It has been reported that autoantibodies against citrullinated type II collagen were produced in RA patients [76, 77]. Meanwhile, collagens including type II are reportedly glucosylated in diabetic patients [78, 79]. Bassiouny proposed that glucosylated collagen may increase antigenicity to initiate autoimmune responses leading to diabetic complications, presumably indicating that $\mathrm{T}$ cells recognize glycosylated type II collagen as "not self" [80]. Although autoantibodies to native type II collagen are also found in the serum of DR and RA patients [19, 20, 81, 82], autoimmune reactions to modified type II collagen seem to be critical for the onset of these diseases, because the coincidence of DR and RA is uncommon as mentioned above.

Conversely, Mimura et al. reported that the frequency of the HLA-DR4-DQ4 haplotype, which was associated with RA, especially in more severe cases [83, 84], was significantly higher in PDR patients than in a non-DR group [85, 86]. HLA-DR and HL-DQ are class II major histocompatibility complex (MHC) antigens, expressed on the surface of antigen-presenting cells, such as macrophages, dendritic cells, and B cells, and determine the productivity of the specific antibodies against proteins. Thus, it is therefore possible that HLA-DR4-DQ4, which are frequently observed in patients with progressed stages of DR and RA, might be involved in the production of some specific autoantibodies. Banerjee et al. found that high levels of anti-native type II collagen antibodies in the serum of RA patients were associated with HLA-DR4 [82]. Matsushita et al. reported that 94 putative DQ4-binding motifs (i.e., amino acid sequences) were detected in the native type II collagen molecules [83]. Cook et al. observed that the presence of antibodies to native type II collagen was associated with the activity of RA and severity of symptoms [32, 45]. As described above, a considerable number of HLA-DQ4-binding motifs were reportedly found in native type II collagen [83], presumably implying that immune response to native type II collagen could be involved in the progression of DR and RA.

\section{Diabetic retinopathy and Arthus reaction}

The joint lesions of RA have been considered to be caused by Arthus reaction, as evidenced by neutrophil infiltration, increased serum and synovial fluid levels of complements and immune complexes, and tissue deposition of immune complexes [33, 87, 88].

The pathological features of Arthus reaction are bleeding, thrombosis, and edema [89], then followed by fibrinoid deposition, as observed in the RA joint [90]. Fibrinoid is mainly composed of fibrin and immune complexes [91], of which deposition has reportedly been detected in the joint tissues of RA patients [92].

We assume that DR in the early stage may also have pathological features of Arthus-like reaction as following 
reasons: (1) neutrophil infiltration into the retinal tissue [10], (2) increased serum levels of complements and immune complexes [19, 93], (3) deposition of immunoglobulins and complements, components of immune complexes, in the retina $[94,95]$. Fu et al. observed that co-staining for oxidized low-density lipoprotein (oxLDL) and IgG was present in the diabetic retina, presumably indicating the deposition of anti-oxLDL immune complexes [96]. Giusti proposed that immune complex deposition in the retina was implicated in the pathogenesis of DR [97]. Retinal bleeding, thrombosis, and edema, all of which are symptoms of Arthus reaction [87], are frequently observed in the relatively early stage of DR [98].

It is sometimes described that hard exudates consist of lipids and/or lipoproteins [99]. However, proteins including fibrin were also reportedly present in hard exudates [100]. Liu et al. demonstrated that lipoprotein (a) [Lp(a)] bound covalently to fibrin, contributing to the deposition of $\mathrm{Lp}(\mathrm{a})$, colocalized with fibrin in atheroma [101]. Smith insisted that fibrin was a factor in lipid accumulation in the atherosclerotic plaque, because fibrin is bound to $\mathrm{Lp}$ (a) with high affinity and also bound to low-density lipoprotein (LDL) [102]. Nogornev proposed that the atherosclerotic plaque was formed by the deposition of immune complexes containing lipoproteins [103]. We assume that fibrin and immune complexes, components of fibrinoid, may form hard exudates along with lipoproteins by a similar mechanism as atheroma plaque formation.

\section{Pericytes and type II collagen}

Pericytes are considered to have mesenchymal stem cell (MSC)-like properties being able to differentiate into chondrocytes, osteoblasts, and adipocytes [104, 105]. FarringtonRock et al. demonstrated that when cultured at high density in the presence of a defined chondrogenic medium, pericytes expressed mRNA of Sox9, a chondrocyte marker, and type II collagen [106].

Ihanamäki et al. have shown that the expression of Sox9 and type IIA procollagen mRNA increased in the developing and aging retina in mice [107]. Swinscoe et al. reported that type II collagen was a major component of the bovine retinal microvessel extracellular matrix [108]. MSCs reportedly tend to undergo chondrogenesis under hypoxia [109, 110]. Hypoxic chondrocytes are also known to produce an increased amount of type II collagen [111, 112]. Besides, high glucose reportedly induces chondrogenesis in MSCs [113]. Chondrogenic differentiation culture medium contains high concentrations of glucose [114]. Accordingly, MSClike pericytes around the retinal vessels may produce type II collagen especially under hypoxia and high-glucose conditions in the diabetic retina.
As mentioned previously, type II collagen produced by pericytes in the diabetic retina will be phagocytized by circulating monocytes/macrophages or retinal microglia, simulating B cells to produce anti-type II collagen antibodies [58-60]. Hypoxia and high-glucose conditions of diabetic retina cause disruption of the blood-retinal barrier [56, 57]. As a result, anti-type II collagen antibodies in the serum may come into contact with type II collagen around the retinal vessels, forming immune complex deposition in the retina.

Selective loss of pericytes occurs in the early stage of DR [115]. It has been reported that increased serum levels of anti-pericyte antibodies were observed in DR patients $[14,17,18]$. In addition to autoimmune responses to type II collagen, anti-pericyte antibodies may injure the pericytes, causing a loss of pericytes in the diabetic retina. A continued loss of pericytes and type II collagen around retinal vessels could result in a shift of the immune response site from the retina to the vitreous and vitreoretinal, where type II collagen is abundantly present [116].

Vitrectomy had been frequently performed to treat DME before anti-VEGF therapy was clinically available [117, 118]. The proposed mechanisms underlying the efficacy of vitrectomy for DME include the elimination of inflammatory cytokines from the vitreous body and the release of vitreoretinal traction $[119,120]$. It has also been shown that vitrectomy significantly increased intraocular oxygen tension for prolonged periods after surgery [121]. Stefánsson proposed that vitrectomy improved retinal oxygenation to reduce DME [122]. Hard exudates, which are lesions that are often observed in DME, can be gradually reduced only by removal of the vitreous body (Fig. 3) [117]. According to the aforementioned assumptions, hard exudates might be anti-type II collagen immune complex deposition along with fibrin and lipoproteins. We speculated that the increased retinal oxygen tension after vitrectomy would suppress the chondrogenic differentiation of pericytes producing type II collagen, resulting in the disappearance of hard exudates containing anti-type II collagen immune complexes.

\section{Müller cells and type II collagen}

Müller cells are the predominant glia of the retina with an elongated shape, spanning across the entire retina [123]. Müller cells not only serve as mechanical support of the neural retina, but also play an important role in the maintenance of its metabolic and physiological homeostasis, including regulation of extracellular environment [123, 124], removal of debris [125], and antigen presentation manifested after removal of suppressive activity [126].

Müller cells have been shown to be capable to phagocytize type II collagen [127, 128], which scarcely exists in the retina under physiological conditions except for the 


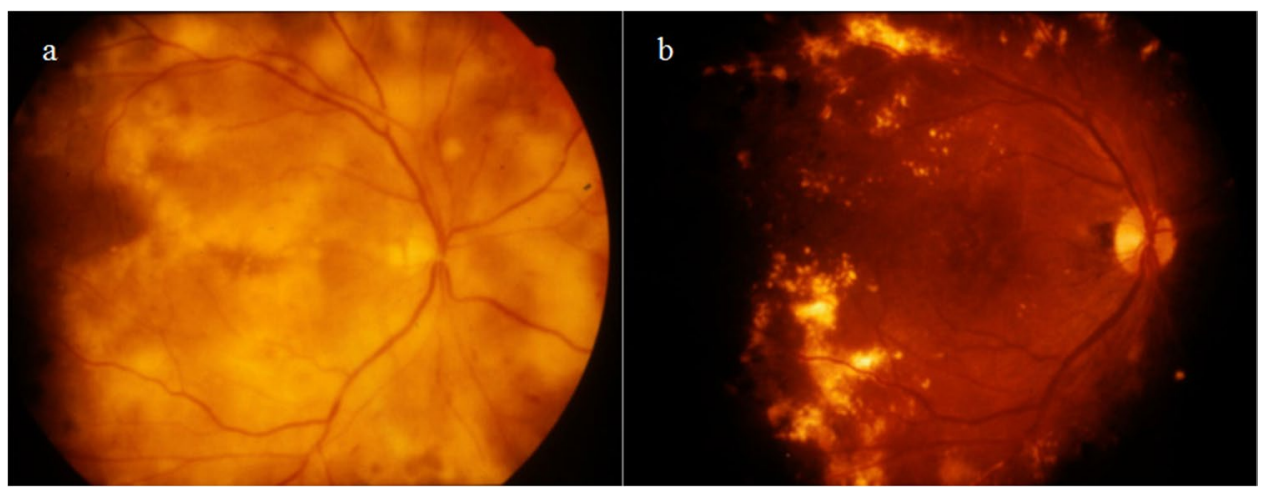

Fig. 3 Ocular fundus photographs in a case of diabetic maculopathy with severe hard exudates before vitrectomy (a) and after vitrectomy (b). The hard exudates in the retina (or in the subretinal space) are gradually reduced only by removing the vitreous body. It is specu-

perivascular area [109]. Removal of type II collagen by Müller cells may suppress autoimmune reactions against it $[127,128]$. On the other hand, the in vitro experiment showed Müller cells synthesized the various collagens of the vitreous and vitreoretinal interface including type II collagen [129]. Müller cells also reportedly expressed the transcription factor Sox 9, which directly regulates COl2A1, the gene encoding type II collagen, during development and injury [130]. We tentatively identified immature Müller cells around the foveola, in which GFAP and vimentin were colocalized [131]. We presume that these immature Müller cells might dedifferentiate and produce type II collagen under hypoxia and high glucose conditions in the diabetic retina, forming foveal hard exudates containing anti-type II collagen immune complexes after a loss of pericytes.

As described above, there is some corroborating evidence that type II collagen is involved in the pathogenesis of DR; however, there are presently limitations to making a specific determination.

\section{Dysregulated innate immunity and multiple autoantibody production in diabetic retinopathy}

As described previously, we observed the serum levels of anti-type II collagen antibodies were higher in patients with non-diabetic DR than in patients with DR [20], indicating that humoral immunity to type II collagen might decrease with the progression of DR. Balashova et al. and Danilova et al. found that cellular immunity was suppressed in DR patients [19, 132]. Loukovaara et al. also reported that $\mathrm{T}$ cell-mediated responses did not dominate in PDR patients [133]. Meanwhile, Graves et al. and Xu et al. indicated that dysregulated innate immune responses associated with inflammation may contribute to the progression of DR [134, lated that the improvement of retinal oxygenation suppresses the chondrogenic differentiation of pericytes, resulting in the disappearance of hard exudates containing anti-type II collagen immune complexes

135]. It has been shown that activated innate immunity promoted angiogenesis and fibrosis [136, 137]. We speculate, therefore, that innate immunity instead of acquired immunity may mainly affect the inflammatory responses as DR progresses.

High levels of autoantibodies to oxLDL and to cardiolipin were observed in the serum of PDR patients [22, 23], although innate immunity seems to be the predominant immune response in PDR as described above. Interestingly, elevated levels of anti-oxLDL and anti-cardiolipin antibodies were also found in the serum of RA patients [138, 139], although anti-oxLDL antibodies in DR patients belonged to the IgA class [21]. These findings also appear to indicate the pathological similarity of DR to RA.

Multiple autoantibodies in the serum are frequently associated with autoimmune diseases, which are caused by a phenomenon called epitope spreading [140-142]. High serum levels of anti-type II collagen antibodies were reportedly associated with the early stage of RA [32, 39], while anticyclic citrullinated peptide (anti-CCP) antibodies increased in the late stage [143], indicating that autoantigens involved in the autoimmune diseases may vary with their progression. Complicated immune responses, including activated innate immunity and multiple autoantibody production, may promote the progression of DR.

\section{Activation of the NLRP3 inflammasome, a critical component of innate immunity, in diabetic retinopathy}

NOD-like receptor family pyrin domain-containing 3 (NLRP3) is a component of inflammasome and a key regulator of innate immunity [144]. NLRP3 inflammasome activation leads to caspase-1-dependent production of IL-1 $\beta$ and IL-18 and to pyroptosis (caspase-1-dependent cell death) [145, 
146]. Subsequently, the above pro-inflammatory cytokines and damage-associated molecular patterns (DAMPs), such as highmobility group box 1 (HMGB1) and adenosine triphosphate (ATP), are released from pyroptotic cells [147, 148].

HMGB1 binds to its receptors, toll-like receptor (TLR)2, TLR4, TLR9, and RAGE (receptor for advanced glycation end products), then activating NLRP3 inflammasome [149, 150]. Extracellular ATP mediates NLRP3 inflammasome activation through the P2X7 receptor [151]. The NLRP3 inflammasome has reportedly been implicated in the pathogenesis of various diseases, including autoimmune diseases such as RA, inflammatory bowel disease (IBD), multiple sclerosis (MS), and type I diabetes [152-154]. It has been demonstrated that the activation of NLRP3 inflammasome promoted pathological angiogenesis and fibrosis in animal experiments $[155,156]$.

High glucose and accumulation of ROS (reactive oxygen species) and AGEs (advanced glycation end products) reportedly activate NLRP3 inflammasome [157-159], and these states are observed in the diabetic retina and vitreous body [79, 160, 161]. Increased DAMPs (e.g., HMGB1 and ATP) released from necrotic and pyroptotic cells in DR may also activate NLRP3 inflammasome [148, 162, 163]. Chen et al. found that increased gene and protein expression of NLRP3 and caspase-1 was observed in peripheral blood monocytes of DR patients compared with that in normal controls [164]. Charmoy et al. reported that NLRP3 inflammasome mediated neutrophil recruitment [165]. Hao et al. indicated that NLRP3 inflammasome activation increased permeability of the blood-retinal barrier [166]. Therefore, exaggerated inflammatory responses, such as persistent leukocyte infiltration and leakage from the retinal vessels, observed in non-PDR with DME are considered to be at least partly caused by the activation of NLRP3 inflammasome $[167,168]$.

Loukovaara et al. found that the levels of inflammasome components, including NLRP 3 and caspase-1, and inflammasome-related pro-inflammatory cytokines, IL-1 $\beta$ and IL-18, were increased in the vitreous of PDR patients [133]. HMGB1 and extracellular ATP, which activated NLRP3 inflammasome, were also reportedly increased in PDR vitreous [169, 170]. Consequently, innate immunity, in which NLRP3 plays a critical role, might be activated throughout all stages of DR, contributing to exacerbation and prolongation of inflammation.

\section{Resemblance of diabetic retinopathy to chronic wound healing}

We consider that the development and progression of DR may closely resemble a prolonged wound healing process. Wound healing is divided into four phases: hemostasis, inflammation, proliferation, and remodeling [171, 172]. Bleeding and blood clotting are observed in the hemostasis phase [173]. Fibrin is involved in clot formation [174]. The inflammation phase is marked by chemotaxis of immune cells, increased vascular permeability, and removal of cellular debris by macrophages [175-177]. The proliferation phase is characterized by angiogenesis and fibroplasia/ fibroblast proliferation [178, 179]. The remodeling phase is where the synthesis of collagen and other extracellular matrix components increases the tensile strength of the wound as it matures [175, 179, 180]. Bleeding, fibrin deposition, and vascular leakage are frequently observed in NPDR [98, 100, 181], and angiogenesis and fibrosis are observed in PDR [182]. We speculate therefore that the former two and the latter two phases of the wound healing process correspond to NPDR and PDR, respectively.

During the inflammation phase of wound healing, proinflammatory M1 macrophages exert functions as antigen presentation, phagocytosis, and production of inflammatory cytokines [183, 184]. After that, during the proliferation phase, anti-inflammatory M2 macrophages stimulate angiogenesis and fibroplasia [185-189]. Macrophage polarization similar to the wound healing process has been observed in DR as described as follows.

Omri et al. reported macrophages expressed inducible nitric oxide synthase (iNOS), a marker of M1 macrophage, migrated through the retina in the animal model of earlystage DR [190]. Arroba et al. also found that microglia, the tissue macrophage of the retina, expressed iNOS increased in the animal model of non-PDR [191]. On the other hand, Kobayashi et al. and Abu El-Asrar et al. demonstrated that CD163-positive M2 macrophages were significantly increased in the vitreous of PDR patients [192, 193].

Reportedly, M1 macrophages produce pro-inflammatory cytokines (including TNF- $\alpha$ and IL-6), inducing neutrophil recruitment and vascular permeability [194, 195], while M2 macrophages produce anti-inflammatory cytokines (including IL-10 and TGF- $\beta$ ) and pro-angiogenic factors (including VEGF and PDGF) [196, 197], promoting angiogenesis and fibrosis [198]. Accordingly, the aforementioned skewing of macrophage phenotype may explain well the pathology of wound healing and DR.

\section{Presumable mechanisms of prolonged inflammatory responses in the diabetic retina}

As described above, M2 macrophages that increase in the advanced stage of wound healing release anti-inflammatory cytokines such as IL-10 and TGF- $\beta$ [196]. M2 macrophages also possess high capacities to produce specialized proresolving mediators (SPMs) such as lipoxins, resolvins, 
protectins, and maresins [199]. SMPs are metabolites of $\omega 3$ and $\omega 6$ polyunsaturated fatty acids, which play key roles in the resolution of inflammation [200]. As a result, the inflammation and proliferation phases of physiological wound healing cease within a relatively short period of time. Namely, the inflammation phase of wound healing typically lasts a couple of days and the proliferation phase occurs up to $2-3$ weeks after injury $[178,201]$. It appears, meanwhile, that the resolution of inflammation is impaired in DR.

Inflammasomes, such as NLRP1, NLRP3, NLRC4, and AIM2, are cytosolic pattern recognition receptors controlling innate immunity [202]. Among them, NLRP3 is the predominant inflammasome activated by tissue injury, contributing to wound healing in the early inflammation phase [203]. As described previously, M2 polarized macrophages produce SPMs, inhibiting the activation of NLRP3 inflammasome [200].

It has been shown that SPMs, such as lipoxin A4 (LXA4) and resolvin $\mathrm{D} 1$ (RvD1), possessed highly potent pro-resolving properties [204, 205], inhibiting the activation of NLRP3 inflammasome and promoting the wound healing [206, 207]. However, it was reported that the levels of LXA4 and RvD1 were reduced in diabetic serum [208-211]. Shi et al. demonstrated high glucose induced a decrease in RvD1 levels in the retina of diabetic mouse [208]. Kaviarasan et al. found that a significant decrease in LXA4 levels was observed in PDR vitreous [211]. ALX/FPR2 and GPR32, the receptors for LXA4 and RvD1 [212], were reportedly downregulated by high glucose in the diabetic retina $[209,210]$. Therefore, the NLRP3 inflammasome activation observed in PDR is presumably increased by high glucose-induced suppression of SPMs and their receptors, causing chronic inflammation with angiogenesis and fibrosis [213, 214].

It has been proposed that the transition from inflammation to proliferation is a critical step during wound healing [177] and that efferocytosis (removal of dying cells by macrophages) provides a key signal to this transition [215, 216]. Efferocytosis reportedly induces macrophage polarization from pro-inflammatory M1 to anti-inflammatory/proangiogenic M2 phenotype [217, 218]. Suresh Babu et al. demonstrated that high glucose conditions induced impairment of efferocytosis in vitro [219]. Khanna et al. found that macrophages isolated from wounds of diabetic mice showed significant impairment in efferocytosis [220].

Freenstra et al. indicated that multiple forms of cell death including apoptosis, necrosis, and pyroptosis were observed in DR [221]. It has been shown that ineffective efferocytosis led to the accumulation of necrotic and pyroptotic cells, releasing DAMPs such as HMGB1 and ATP, which induced vascular permeability [222-225]. DME is frequently sustained without progression to PDR [226], in which high glucose conditions may impair clearance of dying cells by efferocytosis, resulting in the inhibition of macrophage polarization from pro-inflammatory $\mathrm{M} 1$ to anti-inflammatory/pro-angiogenic M2 phenotype [217-220]. Thus, it can be concluded that NLRP3 inflammasome activation by downregulation of SPMs and their receptors as well as inefficient efferocytosis under high glucose conditions may cause persistent inflammation in DR.

\section{Promising new approaches for diabetic retinopathy treatment targeting immunomodulation}

As mentioned previously, various immunosuppressants including corticosteroids have been shown to be effective in treating DR, especially DME [23-27]. Since DR appears to have characteristics of an autoimmune disease, it might be worthwhile to investigate other immunosuppressive or immunomodulating therapies for the treatment of DR [227-230].

Orally administered autoantigens suppress autoimmune diseases in animal models, such as collagen-induced arthritis, experimental allergic encephalomyelitis, uveitis, and type I diabetes, by inducing oral tolerance [48, 49, 231]. Autoantigens of these animal models are type II collagen, myelin, S antigen, and insulin, respectively [231]. Low doses of oral antigen induce antigen-specific $\mathrm{T}$ cell responses, especially those of regulatory $\mathrm{T}$ cells in the gut, releasing anti-inflammatory cytokines including TGF- $\beta$, IL-4, and IL-10 [231, 232]. Human trials of orally administered antigen have shown positive findings in patients with RA and MS [231]. As described previously, anti-type II collagen antibodies increase in the serum before DR is clinically manifested [20]; therefore, oral immune tolerance induction with type II collagen could prevent the onset of DR.

As previously mentioned before, it has been suggested that dysregulation of innate immunity associated with increased inflammatory responses contributes to DR progression $[134,135]$. It has also been shown that the activation of the NLRP3 inflammasome, a key regulator of innate immunity, may cause the exacerbation of macular edema, angiogenesis, and fibrosis [155, 156, 166-168]. Several NLRP3 inhibitors have been investigated for the treatment of DR [233-235]. Zhang et al. demonstrated that MCC950 had protective effects against high glucose-induced human retinal endothelial cell dysfunction [233]. Trotta et al. observed that $\beta$-hydroxybutyrate inhibited diabetic retinal damage through reduction of the NLRP3 inflammasome activation [234]. Isaji et al. reported that tranilast suppressed the proliferation and migration of endothelial cells in vitro and angiogenesis in vivo [235]. As numerous studies have revealed that inhibition of the NLRP3 inflammasome activation was an effective therapeutic approach for autoimmune diseases including RA, MS, and IBD, orally administrable NLRP3 


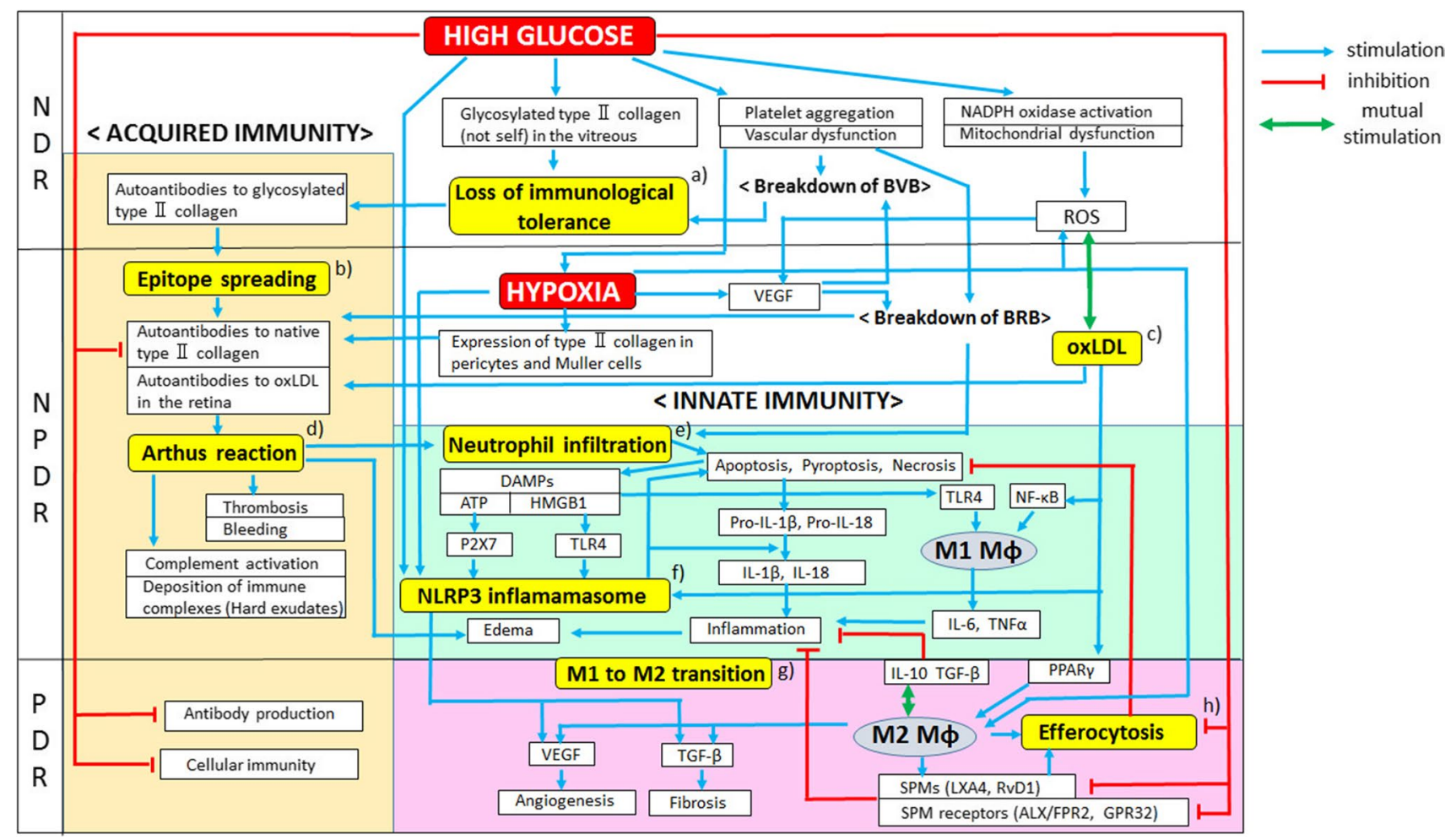

Fig. 4 Schematic overview of our hypothesis on the pathogenesis of DR. Acquired immunity (mainly humoral immunity) is presumably involved in the onset of DR, in which glycosylated type II collagen will be recognized as "not self" by T lymphocytes to initiate immune response [78-80], followed by the deposition of immune complexes, causing Arthus reaction, a type of local type III hypersensitivity [33, 87, 88]. Innate immunity enhances the inflammation, angiogenesis, and fibrosis in DR via the activation of the NLRP3 inflammasome, a key mediator of innate immunity and sterile inflammation [134-136]. High glucose suppresses acquired immunity and inhibits the functions of M2 macrophages, resulting in impaired efferocytosis (phagocytosis of dying cells by macrophages) and suppression of SPMs (promoters of the resolution of inflammation) [219, 220], whereas hypoxia induces M2 macrophage polarization via IL-10 and TGF- $\beta$ [253, 254]. Both high glucose and hypoxia activate innate immunity through NLRP3 inflammasome [134, 135, 164]. a High glucose induces glycosylation of type II collagen in the vitreous [80], along with platelet aggregation and vascular dysfunction that may result in the breakdown of BVB, normally sequestering vitreal type II collagen from the immune system [56, 57, 61]. The recognition of glycosylated type II collagen as "not self" by immune cells can cause the loss of immunological tolerance to it $[43,56,57]$. b Epitope spreading, generally associated with autoimmune diseases such as RA and MS [255], is defined as an autoimmune response that extends from the initial to additional epitopes within the primary target antigen or from the initial autoantigen to unrelated secondary autoantigens [140-142]. Autoantibodies against native type II collagen, type IV collagen, oxLDL, cardiolipin, and platelet other than glycosylated type II collagen are reportedly observed in the serum of DR patients [14, 17-22]. These multiple autoantibodies are probably generated by epitope spreading. c Oxidative stress, such as high glucose and hypoxia, transforms LDL into oxLDL (not self) [256], thus producing autoantibodies and forming immune complexes containing oxLDL in the retina [96]. OxLDL also polarizes macrophages toward the M1 or M2 phenotype via the

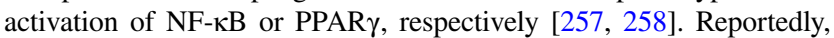
low oxidation degree of oxLDL induces M1 macrophages, whereas high oxLDL induces M2 phenotype [259, 260]. d RA involves Arthustype hypersensitivity accompanied with bleeding, thrombosis, edema, neutrophil infiltration, complement activation, and deposition of immune complexes [33, 87, 88]. These clinical findings of RA are also observed in patients with NPDR [19,93-95], and increased serum levels of autoantibodies to type II collagen are detected in patients with both DR or with RA [20, 31, 32], indicating that these two diseases can have the same etiology. e Neutrophil infiltration into the retina is observed in NPDR [10]. The lifespan of infiltrated neutrophils is short and limited by programmed cell death, including apoptosis and pyroptosis (caspase-1-dependent inflammatory cell death) [221, 261], followed by efferocytosis [217-219]. Dying (or dead) neutrophils release inflammatory cytokines (e.g., IL-1 $\beta$, IL-18) [5] and DAMPs (e.g., HMGB1, ATP) [169, 170], causing retinal inflammation and DME [57, 262]. f High glucose, hypoxia, and DAMPs released from dying cells activate the NLRP3 inflammasome in macrophages, resulting in the activation of caspase- 1 , which cleaves pro-IL-1 $\beta$ and pro-IL-18 into their mature bioactive forms [133]. The activation of the NLRP3 inflammasome also evokes increased levels of VEGF and TGF- $\beta$ in PDR, promoting angiogenesis and fibrosis, respectively $[155,156$, 166]. $g$ The development and progression of DR seem to resemble the process of cutaneous wound healing, although their time courses are different. The transition from the inflammatory to proliferative phase is a critical step of wound healing [177]. During the inflammatory phase, neutrophils infiltrate and M1 macrophages produce proinflammatory cytokines, whereas, during the proliferative phase, M2 macrophages produce anti-inflammatory cytokines and growth factors, promoting angiogenesis and fibroblast proliferation [184-188]. Inflammatory and proliferative phases of wound healing seemingly correspond to NPDR and PDR, respectively. $\mathbf{h}$ Efferocytosis provides a key signal to M1 to M2 transition, thus inducing M2 macrophage polarization [217, 218]. M2 macrophages produce SPMs that possesses highly potent pro-resolving properties $[199,200]$ through inhibiting the activation of NLRP3 inflammasome [206, 207]; however, a high-glucose environment inhibits efferocytosis and SPMs production in DR patients 
inhibitors such as the abovementioned compounds might be promising candidates for the treatment of DR [236-238].

It has been shown that SPMs (including lipoxins and resolvins) and DHA (the precursor of SPMs) inhibited the NLRP3 inflammasome activity, thus being effective for the prevention of DR [239-243]. Since SPMs have short halflives [244], epimers and analogs of SPMs might be clinically more useful than SPMs for the treatment of DR [244-246].

\section{Future issues}

As described previously, the development and progression of DR appear to resemble cutaneous wound healing. NPDR and inflammation phase of diabetic wound healing, namely the early stages of both diseases, are prolonged, associated with persistent infiltration of neutrophils and with increased permeability of blood vessels $[10,56,57]$. Conversely, the proliferation phase of diabetic wound healing is impaired due to insufficient angiogenesis and inhibition of fibroblast proliferation [247-250], whereas exaggerated angiogenesis and fibrosis occur in PDR (Fig. 4) [38, 39].

In addition, the retina has been considered as an extension of the central nervous system (CNS) anatomically and developmentally [251], and the ocular fundus examination is regarded as the observation of non-invasively visualized CNS in cases of patients with hypertension and atherosclerosis [251, 252]; however, angiogenesis never develops in the brain of diabetic patients. Further study is needed to elucidate what causes the difference of angiogenic activity between PDR and the proliferation phase of diabetic wound healing, and what is the anatomical discrepancy of the blood vessels between the retina and brain in relation to angiogenesis.

\footnotetext{
Abbreviations DR: Diabetic retinopathy; IL: Interleukin; TNF$\alpha$ : Tumor necrosis factor-alpha; DME: Diabetic macular edema; NPDR: Non-proliferative diabetic retinopathy; PDR: Proliferative diabetic retinopathy; RA: Rheumatoid arthritis; VEGF: Vascular endothelial growth factor; AIED: Autoimmune ear disease; MHC: Major histocompatibility complex; oxLDL: Oxidized low-density lipoprotein; Lp(a): Lipoprotein (a); LDL: Low-density lipoprotein; MSC: Mesenchymal stem cell; NDR: Non-diabetic retinopathy; NLRP3: NOD-like receptor family pyrin domain-containing 3; DAMPs: Damage-associated molecular patterns; TLR: Toll-like receptor; HMGB1: Highmobility group box 1; ATP: Adenosine triphosphate; IBS: Inflammatory bowel disease; MS: Multiple sclerosis; ROS: Reactive oxygen species; AGEs: Advanced glycation end products; iNOS: Inducible nitric oxide synthase; SPMs: Specialized pro-resolving mediators; LXA4: Lipoxin A4; RvD1: Resolvin D1; BVB: Blood vitreal barrier; BRB: Blood-retinal barrier; МФ: Macrophage; NF-кB: Nuclear factor $\kappa \mathrm{B}$; PPAR $\gamma$ : Peroxisome proliferator-activated receptor $\gamma$; ALX/ FPR2: N-formyl peptide receptor-2; GPR32: G protein-coupled receptor 32; TGF- $\beta$ : Transforming growth factor-beta; TLR4: Toll-like receptor 4 ; NF- $\kappa \beta$ : Nuclear factor $\kappa \beta$; NDR: Non-diabetic retinopathy; MS: Multiple sclerosis
}

Acknowledgements The authors wish to thank John Bush for reviewing the manuscript.

Funding The Japan Society for the Promotion of Science (Tokyo, Japan) provided financial support in the form of a Grant-in-Aid for Scientific Research (C) (No.18K09465). The sponsor had no role in the design or conduct of this research.

\section{Declarations}

Ethical approval All procedures performed in studies involving human participants were in accordance with the ethical standards of the institutional research committee (Ethics Committee of Osaka Medical College; Approval No. 1134) and with the 1964 Helsinki declaration and its later amendments or comparable ethical.

Informed consent Informed consent was obtained from all individual participants included in the study.

Conflict of interest The authors declare no competing interests.

Open Access This article is licensed under a Creative Commons Attribution 4.0 International License, which permits use, sharing, adaptation, distribution and reproduction in any medium or format, as long as you give appropriate credit to the original author(s) and the source, provide a link to the Creative Commons licence, and indicate if changes were made. The images or other third party material in this article are included in the article's Creative Commons licence, unless indicated otherwise in a credit line to the material. If material is not included in the article's Creative Commons licence and your intended use is not permitted by statutory regulation or exceeds the permitted use, you will need to obtain permission directly from the copyright holder. To view a copy of this licence, visit http://creativecommons.org/licenses/by/4.0/.

\section{References}

1. van Hecke MV, Dekker JM, Nijpels G et al (2005) Inflammation and endothelial dysfunction are associated with retinopathy: the Hoorn Study. Diabetologia 48:1300-1306

2. Song J, Chen S, Liu X et al (2015) Relationship between C-reactive protein level and diabetic retinopathy: a systematic review and meta-analysis. PloS One. 10(12):e0144406

3. Nguyen TT, Alibrahim E, Islam FM et al (2009) Inflammatory, hemostatic, and other novel biomarkers for diabetic retinopathy: the multi-ethnic study of atherosclerosis. Diabetes Care 32(9):1704-1709

4. Woo SJ, Ahn SJ, Ahn J et al (2011) Elevated systemic neutrophil count in diabetic retinopathy and diabetes: a hospital-based cross-sectional study of 30,793 Korean subjects. Invest Ophthalmol Vis Sci 52:7697-7703

5. Mao C, Yan H (2014) Roles of elevated intravitreal IL-1 $\beta$ and IL-10 levels in proliferative diabetic retinopathy. Indian J Ophthalmol 62(6):699-701

6. Gustavsson C, Agardh CD, Agardh E (2013) Profile of intraocular tumor necrosis factor- $\alpha$ and interleukin- 6 in diabetic subjects with different degrees of diabetic retinopathy. Acta Ophthalmol 91:445-452

7. Esser P, Heimann K, Wiedemann P (1993) Macrophages in proliferative vitreoretinopathy and proliferative diabetic retinopathy: differentiation of subpopulations. Br J Ophthalmol 77(11):731-733 
8. Tamura K, Yokoyama T, Ebihara N et al (2012) Histopathologic analysis of the internal limiting membrane surgically peeled from eyes with diffuse diabetic macular edema. Jpn J Ophthalmol 56(3):280-287

9. McLeod DS, Lefer DJ, Merges C et al (1995) Enhanced expression of intracellular adhesion molecule-1 and P-selectin in the diabetic human retina and choroid. Am J Pathol 147:642-653

10. Miyamoto K, Hiroshiba N, Tsujikawa A et al (1998) In vivo demonstration of increased leukocyte entrapment in retinal microcirculation of diabetic rats. Invest Ophthalmol Vis Sci 39:2190-2194

11. Lutty GA, Cao J, McLeod DS (1997) Relationship of polymorphonuclear leukocytes to capillary dropout in the human diabetic choroid. Am J Pathol 151:707-714

12. Satofuka S, Ichihara A, Nagai N et al (2009) (Pro)renin receptor-mediated signal transduction and tissue renin-angiotensin system contribute to diabetes-induced retinal inflammation. Diabetes 58:1625-1633

13. Kastelan S, Zjacić-Rotkvić V, Kastelan Z (2007) Could diabetic retinopathy be an autoimmune disease? Med Hypotheses 68:1016-1018

14. Adams DD (2008) Autoimmune destruction of pericytes as the cause of diabetic retinopathy. Clin Ophthalmol 2(2):295-298

15. Cisse A, Chevenne D, Chauffert M et al (1998) HLA-markers and diabetic retinopathy in the Senegalese population. Dakar Med 43(1):29-33

16. Birinci A, Birinci H, Abidinoglu R et al (2002) Diabetic retinopathy and HLA antigens in type 2 diabetes mellitus. Eur $\mathbf{J}$ Ophthalmol 12(2):89-93

17. Nayak RC, Agardh CD, Kwok MG et al (2003) Circulating anti-pericyte autoantibodies are present in Type 2 diabetic patients and are associated with non-proliferative retinopathy. Diabetologia 46:511-513

18. Attawia MA, Nayak RC (1999) Circulating antipericyte autoantibodies in diabetic retinopathy. Retina 19:390-400

19. Balashova LM, Zătseva NS, Teplinskaia LE et al (2000) Antibodies to types II and IV collagens, tumor necrosis factor-alpha and circulating immune complexes in lacrimal fluid and serum of patients with diabetic retinopathy and different stages. Vestn Oftalmol 116:31-34

20. Nakaizumi A, Fukumoto M, Kida T et al (2015) Measurement of serum and vitreous concentrations of anti-type II collagen antibody in diabetic retinopathy. Clin Ophthalmol 9:543-547

21. Vavuli S, Salonurmi T, Loukovaara S, et.al (2016) Elevated levels of plasma IgA autoantibodies against oxidized LDL found in proliferative diabetic retinopathy but not in nonproliferative retinopathy. J Diabetes Res. 2016:2614153

22. Shahin M, El-Diasty AM, Mabed M (2009) Anticardiolipin antibodies in proliferative diabetic retinopathy: an additional risk factor. Saudi J Ophthalmol 23(2):165-169

23. Falavarjani KG, Golabi S, Modarres M (2016) Intravitreal injection of methotrexate in persistent diabetic macular edema: a 6-month follow-up study. Graefes Arch Clin Exp Ophthalmol. 254(11):2159-2164

24. Dugel PU, Blumenkranz MS, Haller JA et al (2012) A randomized, dose-escalation study of subconjunctival and intravitreal injections of sirolimus in patients with diabetic macular edema. Ophthalmology 119:124-131

25. Zong YJ, Shen Q, Zhang XD et al (2012) The protective effects on the function and structure of retinae in diabetic rats by intravitreal injection of cyclosporin A. Zhonghua Yan Ke Za Zhi 48:591-597

26. Sfikakis PP, Markomichelakis N, Theodossiadis GP et al (2005) Regression of sight-threatening macular edema in type 2 diabetes following treatment with the anti-tumor necrosis factor monoclonal antibody infliximab. Diabetes Care 28(2):445-447
27. Guilpain P, Le Jeunne C (2012) Anti-inflammatory and immunosuppressive properties of corticosteroids. Presse Med 41(4):378-383

28. Holmdahl R, Malmström V, Burkhardt H (2014) Autoimmune priming, tissue attack and chronic inflammation - the three stages of rheumatoid arthritis. Eur J Immunol 44(6):1593-1599

29. Xia ZB, Meng FR, Fang YX et al (2018) Inhibition of NF- $\kappa B$ signaling pathway induces apoptosis and suppresses proliferation and angiogenesis of human fibroblast-like synovial cells in rheumatoid arthritis. Medicine (Baltimore). 97(23):e10920

30. Ruberti JW, Sokoloff JB (2011) Theory of the short time mechanical relaxation in articular cartilage. J Biomech Eng. 133(10): 104504

31. Terato K, Shimozuru Y, Katayama K et al (1990) Specificity of antibodies to type II collagen in rheumatoid arthritis. Arthritis Rheum 33:1493-1500

32. Cook AD, Rowley MJ, Mackay IR et al (1996) Antibodies to type II collagen in early rheumatoid arthritis. Correlation with disease progression Arthritis Rheum 39:1720-1727

33. Kitsis E, Weissmann G (1991) The role of the neutrophil in rheumatoid arthritis. Clin Orthop Relat Res 265:63-72

34. Li Y, Liu Y, Wang C et al (2018) Succinate induces synovial angiogenesis in rheumatoid arthritis through metabolic remodeling and HIF-1 $\alpha /$ VEGF axis. Free Radic Biol Med 126:1-14

35. Nonomura Y, Mizoguchi F, Suzuki A (2009) Hypoxia-induced abrogation of contact-dependent inhibition of rheumatoid arthritis synovial fibroblast proliferation. J Rheumatol 36(4):698-705

36. Maini RN (1979) Immunopathological mechanisms in rheumatoid arthritis at the dual interface of the synovial membrane: the joint cavity and the pannus. Rheumatol Rehabil. Suppl:20-29.

37. Wang X, Wang G, Wang Y (2009) Intravitreous vascular endothelial growth factor and hypoxia-inducible factor $1 \mathrm{a}$ in patients with proliferative diabetic retinopathy. Am J Ophthalmol 148(6):883-889

38. Bringmann A, Pannicke T, Uhlmann S et al (2002) Membrane conductance of Müller glial cells in proliferative diabetic retinopathy. Can J Ophthalmol 37(4):221-227

39. Mullazehi M, Wick MC, Klareskog L et al (2012) Antitype II collagen antibodies are associated with early radiographic destruction in rheumatoid arthritis. Arthritis Res Ther 14(3):R100

40. Moder KG, Nabozny GH, Luthra HS et al (1992) Immunogenetics of collagen induced arthritis in mice: a model for human polyarthritis. Reg Immunol 4(5):305-313

41. Wooley PH, Chapedelaine JM (1987) Immunogenetics of collagen-induced arthritis. Crit Rev Immunol 8:1-22

42. Misaki Y, Yamamoto K (1999) Immunological tolerance and autoimmune disease. Nihon Rinsho 57(8):1703-1709

43. Alivernini S, Fedele AL, Cuoghi I et al (2008) Citrullination: the loss of tolerance and development of autoimmunity in rheumatoid arthritis. Reumatismo 60(2):85-94

44. Klareskog L, Johnell O, Hulth A et al (1986) Reactivity of monoclonal anti-type II collagen antibodies with cartilage and synovial tissue in rheumatoid arthritis and osteoarthritis. Arthritis Rheum 29(6):730-738

45. Cook AD, Mackay IR, Cicuttini FM et al (1997) IgG subclasses of antibodies to type II collagen in rheumatoid arthritis differ from those in systemic lupus erythematosus and other connective tissue diseases. J Rheumatol 24(11):2090-2096

46. Kim HA, Seo YI, Lee J et al (2016) Detection of anti-type II collagen antibodies in patients with chronic gouty arthritis: findings from a pilot study. J Clin Rheumatol 22(7):360-363

47. Gu ZY (1991) Immunohistochemical study of temporomandibular joint disturbance syndrome. Zhonghua Kou Qiang Yi Xue Za Zhi. 26(5):300-302, 318. 
48. Park KS, Park MJ, Cho ML et al (2009) Type II collagen oral tolerance; mechanism and role in collagen-induced arthritis and rheumatoid arthritis. Mod Rheumatol 19:581-589

49. Toussirot EA (2002) Oral tolerance in the treatment of rheumatoid arthritis. Curr Drug Targets Inflamm Allergy 1(1):45-52

50. Stancikova M, Stancik R, Gubzova Z et al (1999) Collagen in the treatment of rheumatic diseases-oral tolerance. Bratisl Lek Listy 100(10):567-571

51. Yoshino K, Ohashi T, Urushibata T et al (1996) Antibodies of type II collagen and immune complexes in Menière's disease. Acta Otolaryngol Suppl 522:79-85

52. Yoo TJ, Stuart JM, Kang AH et al (1982) Type II collagen autoimmunity in otosclerosis and Meniere's disease. Science 217:1153-1155

53. Yoo TJ, Lee MK, Min YS et al (1994) Epitope specificity and T cell receptor usage in type II collagen induced autoimmune ear disease. Cell Immunol 157(1):249-262

54. Ohashi T, Tomoda K, Yoshie N (1989) Electrocochleographic changes in endolymphatic hydrops induced by type II collagen immunization through the stylomastoid foramen. Ann Otol Rhinol Laryngol 98:556-562

55. Takeda T, Sudo N, Kitano H et al (1996) Type II collageninduced autoimmune ear disease in mice: a preliminary report on an epitope of the type II collagen molecule that induced inner ear lesions. Am J Otol 17(1):69-75

56. Kaur C, Sivakumar Kaur C et al (2007) Blood-retinal barrier disruption and ultrastructural changes in the hypoxic retina in adult rats: the beneficial effect of melatonin administration. $\mathbf{J}$ Pathol 212(4):429-439

57. Platania CBM, Lazzara F, Fidilio A et al (2019) Blood-retinal barrier protection against high glucose damage: The role of $\mathrm{P} 2 \mathrm{X} 7$ receptor. Biochem Pharmacol 168:249-258

58. Catchpole B, Staines NA, Hamblin AS (2001) Antigen presentation of type II collagen in rats. Clin Exp Immunol 125(3):478-484

59. Matsubara T, Pararajasegaram G, Wu GS et al (1999) Retinal microglia differentially express phenotypic markers of antigen-presenting cells in vitro. Invest Ophthalmol Vis Sci 40(13):3186-3193

60. O'Keefe GM, Nguyen VT, Benveniste EN (1999) Class II transactivator and class II MHC gene expression in microglia: modulation by the cytokines TGF-beta, IL-4, IL-13 and IL-10. Eur J Immunol 29(4):1275-1285

61. Raviola G (1977) The structural basis of the blood-ocular barriers. Exp Eye Res 25(Suppl):27-63

62. Knight AD, Levick JR (1984) Morphometry of the ultrastructure of the blood-joint barrier in the rabbit knee. Q J Exp Physiol 69(2):271-288

63. Juhn SK, Hunter BA, Odland RM (2001) Blood-labyrinth barrier and fluid dynamics of the inner ear. Int Tinnitus J 7:72-83

64. Tsuchida T (2002) Clinical evaluation of high molecular hyaluronic acid (HA) on rheumatoid arthritic knees. Clin Calcium 12(1):112-116

65. Lopez-Escamez JA, Attyé A (2019) Systematic review of magnetic resonance imaging for diagnosis of Meniere disease. $\mathbf{J}$ Vestib Res 29(2-3):121-129

66. Ikeda T, Nakamura K, Oku H et al (2015) The role of tryptase and anti-type II collagen antibodies in the pathogenesis of idiopathic epiretinal membranes. Clin Ophthalmol 9:1181-1186

67. Bartels CM, Wong JC, Johnson SL et al (2015) Rheumatoid arthritis and the prevalence of diabetic retinopathy. Rheumatology (Oxford) 54:1415-1419

68. Singal DP, Li J, Zhu Y (1999) Genetic basis for rheumatoid arthritis. Arch Immunol Ther Exp (Warsz) 47:307-311

69. Snir O, Rieck M, Gobe JA et al (2011) Identification and functional characterization of $\mathrm{T}$ cells reactive to citrullinated vimentin in HLA-DRB1*0401-positive humanized mice and rheumatoid arthritis patients. Arthritis Rheum 63(10):2873-2883

70. Auger I, Roudier J (2005) Interaction between HSP73 and HLADRB 1*0401: implications for the development of rheumatoid arthritis. Immunol Res 31(3):261-266

71. Kim HY, Kim TG, Park SH et al (1995) Predominance of HLADRB $1 * 0405$ in Korean patients with rheumatoid arthritis. Ann Rheum Dis 54(12):988-990

72. Flipo RM, Danze PM, Castelain V, et al (1993) [Systemic manifestations of rheumatoid arthritis: prognostic value of the HLA DRB1 0405 allele]. [Article in French] Rev Med Interne. 14 (10), 10141993.

73. Gomez A, Luckey D, Yeoman CJ et al (2012) Loss of sex and age driven differences in the gut microbiome characterize arthritis-susceptible 0401 mice but not arthritis-resistant 0402 Mice. PLoS One. 7(4):e36095

74. Das P, Bradley DS, Geluk A (1999) An HLA-DRB1*0402 derived peptide (HV3 65-79) prevents collagen-induced arthritis in HLA-DQ8 transgenic mice. Hum Immunol 60(7):575-582

75. Sn K, Tomić M, Salopek-Rabatić J et al (2013) The association between the HLA system and retinopathy development in patients with type 1 diabetes mellitus. Coll Antropol 37(Suppl 1):65-70

76. Koivula MK, Heliövaara M, Ramberg J et al (2007) Autoantibodies binding to citrullinated telopeptide of type II collagen and to cyclic citrullinated peptides predict synergistically the development of seropositive rheumatoid arthritis. Ann Rheum Dis 66:1450-1455

77. Burkhardt H, Sehnert B, Bockermann R et al (2005) Humoral immune response to citrullinated collagen type II determinants in early rheumatoid arthritis. Eur J Immunol 35:1643-1652

78. Schnider SL, Kohn RR (1981) Effects of age and diabetes mellitus on the solubility and nonenzymatic glucosylation of human skin collagen. J Clin Invest 67(6):1630-1635

79. Lundquist O, Osterlin S (1994) Glucose concentration in the vitreous of nondiabetic and diabetic human eyes. Graefes Arch Clin Exp Ophthalmol 232(2):71-74

80. Bassiouny AR, Rosenberg H, McDonald TL (1983) Glucosylated collagen is antigenic. Diabetes 32(12):1182-1184

81. Gioud M, Meghlaoui A, Costa O et al (1982) Antibodies to native type I and II collagens detected by an enzyme linked immunosorbent assay (ELISA) in rheumatoid arthritis and systemic lupus erythematosus. Coll Relat Res 2(6):557-564

82. Banerjee S, Luthra HS, Moore SB et al (1988) Serum IgG antinative type II collagen antibodies in rheumatoid arthritis: association with HLA DR4 and lack of clinical correlation. Clin Exp Rheumatol 6(4):373-380

83. Matsushita S, Nishi T, Oiso M et al (1996) HLA-DQ-binding peptide motifs 1 Comparative binding analysis of type II collagen-derived peptides to DR and DQ molecules of rheumatoid arthritis-susceptible and non-susceptible haplotypes. Int Immunol. 8(5):757-764

84. Yuan G, Shi G, Li Z (1997) DNA Typing for HLA-DR and HLADQ alleles in Chinese patients with rheumatoid arthritis. Zhonghua Nei Ke Za Zhi 36(4):234-237

85. Mimura T, Funatsu H, Uchigata Y et al (2003) Relationship between human leukocyte antigen status and proliferative diabetic retinopathy in patients with younger-onset type 1 diabetes mellitus. Am J Ophthalmol 135:844-848

86. Mimura T, Funatsu H, Uchigata Y et al (2005) Glutamic acid decarboxylase autoantibody prevalence and association with HLA genotype in patients with younger-onset type 1 diabetes and proliferative diabetic retinopathy. Ophthalmology 112(11):1904-1909 
87. Hester RB, Bennett JC (1973) Rheumatoid arthritis: an immune complex disease? A review of the reaction of antigen with antibody to form immune complexes and the mechanisms by which they mediate tissue injury. Geriatrics 28:84-91

88. Li W, Li H, Song W et al (2013) Differential diagnosis of systemic lupus erythematosus and rheumatoid arthritis with complements $\mathrm{C} 3$ and $\mathrm{C} 4$ and C-reactive protein. Exp Ther Med 6(5):1271-1276

89. Dhodapkar BS, Vegad JL, Dhawedkar RG et al (1984) Pathology of reversed passive Arthus reaction in the chicken. Avian Pathol 13(1):93-108

90. Goto H (1988) Incidence and location of synovitis in the metatarso-phalangeal joints of the fore and hindlimbs of rabbits immunized with Escherichia coli. Nihon Seikeigeka Gakkai Zasshi 62(3):255-266

91. Gazit D, Nahlieli O, Neder A et al (1991) Leukocytoclastic vasculitis (anaphylactoid purpura): a unique occurrence in the oral cavity. J Oral Pathol Med 20(10):509-511

92. Hertel E, Bartels J (1976) The presence of fluorescein-conjugated antibodies in synovial tissues of rheumatic joints. $\mathrm{Z}$ Rheumatol 35(5-6):195-200

93. Rasmussen KL, Nordestgaard BG, Nielsen SF (2018) Complement $\mathrm{C} 3$ and risk of diabetic microvascular disease: a cohort study of 95202 individuals from the general population. Clin Chem 64(7):1113-1124

94. Zhang X, Qiu JCM, Li D et al (2008) The effects of cyclosporine A on immunoglobulins deposition in retina of streptozotocin-induced diabetic rats. Zhonghua Nei Ke Za Zhi 47(2):125-128

95. Zhang J, Gerhardinger C, Lorenzi M (2002) Early complement activation and decreased levels of glycosylphosphatidylinositolanchored complement inhibitors in human and experimental diabetic retinopathy. Diabetes 51(12):3499-3504

96. Fu D, Yu JY, Wu M et al (2014) Immune complex formation in human diabetic retina enhances toxicity of oxidized LDL towards retinal capillary pericytes. J Lipid Res 55(5):860-869

97. Giusti C (2004) Are phospholipid-binding antibodies implicated in the pathogenesis of diabetic microangiopathy. Med Hypotheses 63(2):235-238

98. Murugesan N, Üstunkaya T, Feener EP (2015) Thrombosis and hemorrhage in diabetic retinopathy: a perspective from an inflammatory standpoint. Semin Thromb Hemost 41(6):659-664

99. Yanoff M (1969) Ocular pathology of diabetes mellitus. Am J Ophthalmol 67(1):21-38

100. Murata T, Ishibashi T, Inomata H (1992) Immunohistochemical detection of extravasated fibrinogen (fibrin) in human diabetic retina. Graefes Arch Clin Exp Ophthalmol 230(5):428-431

101. Liu JN, Kung W, Harpel PC et al (1998) Demonstration of covalent binding of lipoprotein(a) $[\mathrm{Lp}(\mathrm{a})]$ to fibrin and endothelial cells. Biochemistry 37(11):3949-3954

102. Smith EB (1994) Lipids and plasma fibrinogen: early and late composition of the atherosclerotic plaque. Cardiologia 39(12 Suppl 1):169-172

103. Nagornev VA (1995) Atherogenesis and immune inflammation. Arkh Patol 57(3):6-14

104. da Silva ML, Bellagamba BC, Camassola M et al (2016) Mesenchymal stem cells and their relationship to pericytes. Front Biosci (Landmark Ed) 21:130-156

105. de Souza LE, Malta TM, Kashima Haddad S et al (2016) Mesenchymal stem cells and pericytes: to what extent are they related? Stem Cells Dev 25:1843-1852

106. Farrington-Rock C, Crofts NJ, Doherty MJ et al (2004) Chondrogenic and adipogenic potential of microvascular pericytes. Circulation 110:2226-2232

107. Ihanamäki T, Säämänen AM, Suominen J et al (2002) Expression of Sox 9 and type IIA procollagen during ocular development and aging in transgenic Del1 mice with a mutation in the type II collagen gene. Eur J Ophthalmol 12:450-458

108. Swinscoe JC, Carlson EC (1995) Type II collagen is a major component of bovine retinal microvessel extracellular matrix. Microcirculation 2:253-265

109. Robins JC, Akeno N, Mukherjee A et al (2005) Hypoxia induces chondrocyte-specific gene expression in mesenchymal cells in association with transcriptional activation of Sox9. Bone 37:313-322

110. Kanichai M, Ferguson D, Prendergast PJ et al (2008) Hypoxia promotes chondrogenesis in rat mesenchymal stem cells: a role for AKT and hypoxia-inducible factor (HIF)-1alpha. J Cell Physiol 216:708-715

111. Lafont JE, Poujade FA, Pasdeloup M et al (2016) Hypoxia potentiates the BMP-2 driven COL2A1 stimulation in human articular chondrocytes via $\mathrm{p} 38$ MAPK. Osteoarthritis Cartilage 24(5):856-867

112. Duval E, Leclercq S, Elissalde JM et al (2009) Hypoxia-inducible factor 1alpha inhibits the fibroblast-like markers type I and type III collagen during hypoxia-induced chondrocyte redifferentiation: hypoxia not only induces type II collagen and aggrecan, but it also inhibits type I and type III collagen in the hypoxia-inducible factor 1alpha-dependent redifferentiation of chondrocytes. Arthritis Rheum 60(10):3038-3048

113. Tsai TL, Manner PA, Li WJ (2013) Regulation of mesenchymal stem cell chondrogenesis by glucose through protein kinase $\mathrm{C} /$ transforming growth factor signaling. Osteoarthritis Cartilage $21: 368-376$

114. Zhang XQ, Li X, Wu T et al (2009) Isolation, culture and chondrogenic differentiation of goat bone marrow mesenchymal stem cells. Nan Fang Yi Ke Da Xue Xue Bao 29(3):419-422

115. Beltramo E, Porta M (2013) Pericyte loss in diabetic retinopathy: mechanisms and consequences. Curr Med Chem 20(26):3218-3225

116. Ponsioen TL, van Luyn MJ, van der Worp RJ et al (2008) Collagen distribution in the human vitreoretinal interface. Invest Ophthalmol Vis Sci 49:4089-4095

117. Hoerle S, Poestgens H, Schmidt J et al (2002) Effect of pars plana vitrectomy for proliferative diabetic vitreoretinopathy on preexisting diabetic maculopathy. Graefes Arch Clin Exp Ophthalmol 240(3):197-201

118. Martina Tomić M, Vrabec R, Poljičanin T et al (2017) Diabetic macular edema: traditional and novel treatment. Acta Clin Croa 56(1):124-132

119. Okunuki Y, Usui Y, Katai N et al (2011) Relation of intraocular concentrations of inflammatory factors and improvement of macular edema after vitrectomy in branch retinal vein occlusion. Am J Ophthalmol 151(4):610-616

120. Lewis H, Abrams GW, Blumenkranz MS et al (1992) Vitrectomy for diabetic macular traction and edema associated with posterior hyaloidal traction. Ophthalmology 99:753-759

121. Holekamp NM, Shui YB, Beebe DC (2005) Vitrectomy surgery increases oxygen exposure to the lens: a possible mechanism for nuclear cataract formation. Am J Ophthalmol 139(2):302-310

122. Stefánsson E (2001) The therapeutic effects of retinal laser treatment and vitrectomy A theory based on oxygen and vascular physiology. Acta Ophthalmol Scand. 79(5):435-440

123. Bringmann A, Pannicke T, Grosche J et al (2006) Müller cells in the healthy and diseased retina. Prog Retin Eye Res 25:397-424

124. Esguerra M, Miller RF (2002) CD38 expression and NAD+induced intracellular $\mathrm{Ca}+$ mobilization in isolated retinal Müller cells. Glia 39(3):314-319 
125. Bejarano-Escobar R, Sánchez-Calderón H, Otero-Arenas J et al (2017) Müller glia and phagocytosis of cell debris in retinal tissue. J Anat 231(4):471-483

126. Roberge FG, Caspi RR, Nussenblatt RB (1988) Glial retinal Müller cells produce IL-1 activity and have a dual effect on autoimmune $\mathrm{T}$ helper lymphocytes Antigen presentation manifested after removal of suppressive activity. J Immunol. 140(7):2193-2196

127. Ponsioen TL, van Luyn MJ, van der Worp RJ et al (2007) In vitro phagocytosis of collagens by immortalised human retinal Müller cells. Graefes Arch Clin Exp Ophthalmol 245:82-92

128. Ponsioen TL, van der Worp RJ, van Luyn MJ et al (2005) Packages of vitreous collagen (type II) in the human retina: an indication of postnatal collagen turnover? Exp Eye Res 80:643-650

129. Ponsioen TL, van Luyn MJ, van der Worp RJ et al (2008) Human retinal Müller cells synthesize collagens of the vitreous and vitreoretinal interface in vitro. Mol Vis 14:652-660

130. Wang X, Fan J, Zhang M et al (2013) Upregulation of SOX9 in glial (Müller) cells in retinal light damage of rats. Neurosci Lett 556:140-145

131. Ikeda T, Nakamura K, Oku H et al (2019) Immunohistological study of monkey foveal retina. Sci Rep 9(1):5258

132. Danilova A, Dekhtiareva OS (1984) Cellular immunity in patients with diabetes mellitus complicated by diabetic retinopathies. Probl Endokrinol (Mosk) 30:29-34

133. Loukovaara S, Piippo N, Kinnunen K et al (2017) NLRP3 inflammasome activation is associated with proliferative diabetic retinopathy. Acta Ophthalmol 95(8):803-808

134. Graves DT, Kayal RA (2008) Diabetic complications and dysregulated innate immunity. Front Biosci 13:1227-1239

135. Xu H, Chen M (2017) Diabetic retinopathy and dysregulated innate immunity. Vision Res 139:39-46

136. Frantz S, Vincent AK, Feron $\mathrm{O}$ et al (2005) Innate immunity and angiogenesis. Circ Res 96(1):15-26

137. Jeong WI, Gao B (2008) Innate immunity and alcoholic liver fibrosis. J Gastroenterol Hepatol, 23 Suppl 1 (Suppl 1), S112-118.

138. Nowak B, Madej M, Łuczak A et al (2016) Disease activity, oxidized-LDL fraction and anti-oxidized LDL antibodies influence cardiovascular risk in rheumatoid arthritis. Adv Clin Exp Med 25(1):43-50

139. Jeleniewicz R, Majdan M, Targońska-Stępniak B et al (2012) Prevalence of antiphospholipid antibodies in rheumatoid arthritis patients and relationship with disease activity. Pol Arch Med Wewn 122(10):480-486

140. Brink M, Hansson M, Mathsson L et al (2013) Multiplex analyses of antibodies against citrullinated peptides in individuals prior to development of rheumatoid arthritis. Arthritis Rheum 65:899-910

141. Powell AM, Black MM (2001) Epitope spreading: protection from pathogens, but propagation of autoimmunity? Clin Exp Dermatol 26(5):427-433

142. Csorba TR, Lyon AW, Hollenberg MD (2010) Autoimmunity and the pathogenesis of type 1 diabetes. Crit Rev Clin Lab Sci 47(2):51-71

143. Lundberg K, Nijenhuis S, Vossenaar ER et al (2005) Citrullinated proteins have increased immunogenicity and arthritogenicity and their presence in arthritic joints correlates with disease severity. Arthritis Res Ther 7:R458-467

144. Takahashi H, Okayama N, Yamaguchi N et al (2017) Associations of interactions between NLRP3 SNPs and HLA mismatch with acute and extensive chronic graft-versus-host diseases. Sci Rep 7(1):13097

145. Cao Y, Li Y, Chen R et al (2016) Effect of NLRP3 inflammasome on vascular diseases. Zhong Nan Da Xue Xue Bao Yi Xue Ban 41(11):1232-1236
146. Fu Q, Wu J, Zhou XY et al (2019) NLRP3/Caspase-1 Pathwayinduced pyroptosis mediated cognitive deficits in a mouse model of sepsis-associated encephalopathy. Inflammation 42(1):306-318

147. Jorgensen I, Lopez JP, Laufer SA et al (2016) IL-1 $\beta$, IL-18, and eicosanoids promote neutrophil recruitment to poreinduced intracellular traps following pyroptosis. Eur J Immunol 46(12):2761-2766

148. Magna M, Pisetsky DS (2015) The role of cell death in the pathogenesis of SLE: Is pyroptosis the missing link? Scand J Immunol 82(3):218-224

149. Lippai D, Bala S, Petrasek J et al (2013) Alcohol-induced IL- $1 \beta$ in the brain is mediated by NLRP3/ASC inflammasome activation that amplifies neuroinflammation. J Leukoc Biol 94(1):171-182

150. Thankam FG, Roesch ZK, Dilisio MF et al (2018) Association of inflammatory responses and ECM disorganization with HMGB1 upregulation and NLRP3 inflammasome activation in the injured rotator cuff tendon. Sci Rep 8(1):8918

151. Karmakar M, Katsnelson MA, Dubyak GR et al (2016) Neutrophil P2X7 receptors mediate NLRP3 inflammasome-dependent IL-1 $\beta$ secretion in response to ATP. Nat Commun 7:10555

152. Guo C, Fu R, Wang S et al (2018) NLRP3 inflammasome activation contributes to the pathogenesis of rheumatoid arthritis. Clin Exp Immunol 194(2):231-243

153. Tartey S, Kanneganti TD (2019) Differential role of the NLRP3 inflammasome in infection and tumorigenesis. Immunology 156(4):329-338

154. Tai N, Wong FS, Wen L (2016) The role of the innate immune system in destruction of pancreatic beta cells in NOD mice and humans with type I diabetes. J Autoimmun 71:26-34

155. Chaurasia SS, Lim RRm, Parikh BH, et al (2018) The NLRP3 inflammasome may contribute to pathologic neovascularization in the advanced stages of diabetic retinopathy. Sci Rep 8(1):2847

156. Hishida E, Ito H, Komada K et al (2019) Crucial role of NLRP3 inflammasome in the development of peritoneal dialysis-related peritoneal fibrosis. Sci Rep 9(1):10363

157. Lu L, Qianyi Lu Q, Chen W, et al (2018) Vitamin D3 protects against diabetic retinopathy by inhibiting high-glucose-induced activation of the ROS/TXNIP/NLRP3 inflammasome pathway. J Diabetes Res. eCollection 8193523.

158. Zhang X, Fu Y, Li H et al (2018) H3 relaxin inhibits the collagen synthesis via ROS- and P2X7R-mediated NLRP3 inflammasome activation in cardiac fibroblasts under high glucose. J Cell Mol Med 22(3):1816-1825

159. Kong X, Ai-Ling Lu AL, Yao XM, et al (2017) Activation of NLRP3 inflammasome by advanced glycation end products promotes pancreatic islet damage. Oxid Med Cell Longev. 9692546.

160. Yeh PT, Yang CM, Huang JS et al (2008) Vitreous levels of reactive oxygen species in proliferative diabetic retinopathy. Ophthalmology 115(4):734-737

161. Stitt AW, Moore JE, Sharkey JA et al (1998) Advanced glycation end products in vitreous: structural and functional implications for diabetic vitreopathy. Invest Ophthalmol Vis Sci 39:2517-2523

162. Zhang Weili, Lavine KJ et al (2015) Necrotic myocardial cells release damage- associated molecular patterns that provoke fibroblast activation in vitro and trigger myocardial inflammation and fibrosis in vivo. J Am Heart Assoc. 4(6):e001993

163. Zeng C, Wang R, Tan H (2019) Role of pyroptosis in cardiovascular diseases and its therapeutic implications. Int J Biol Sci 15(7):1345-1357

164. Chen H, Zhang X, Liao N et al (2018) Enhanced expression of NLRP3 inflammasome-related inflammation in diabetic retinopathy. Invest Ophthalmol Vis Sci 59(2):978-985 
165. Charmoy M, Hurrell BP, Romano A et al (2016) The Nlrp3 inflammasome, IL-1 $\beta$, and neutrophil recruitment are required for susceptibility to a nonhealing strain of Leishmania major in C57BL/6 mice. Eur J Immunol 46(4):897-911

166. Hao J, Zhang H, Yu J et al (2019) Methylene blue attenuates diabetic retinopathy by inhibiting NLRP3 inflammasome activation in STZ-induced diabetic rats. Ocul Immunol Inflamm 27(5):836-884

167. Amaral FA, Costa VV, Tavares LD et al (2012) NLRP3 inflammasome-mediated neutrophil recruitment and hypernociception depend on leukotriene B(4) in a murine model of gout. Arthritis Rheum 64(2):474-484

168. Xu F, Shen S, Su Z et al (2019) Glibenclamide ameliorates the disrupted blood-brain barrier in experimental intracerebral hemorrhage by inhibiting the activation of NLRP3 inflammasome. Brain Behav. 4:e01254

169. El-Asrar AMA, Nawaz MI, Kangave D et al (2011) Highmobility group box-1 and biomarkers of inflammation in the vitreous from patients with proliferative diabetic retinopathy. Mol Vis 17:1829-1838

170. Loukovaara S, Sahanne S, Jalkanen S et al (2015) Increased intravitreal adenosine 5'-triphosphate, adenosine 5'-diphosphate and adenosine 5 '-monophosphate levels in patients with proliferative diabetic retinopathy. Acta Ophthalmol 93(1):67-73

171. Velnar T, Bailey T, T, Smrkol V, (2009) The wound healing process: an overview of the cellular and molecular mechanisms. J Int Med Res 37:1528-1542

172. Laitiff AA, Teoh SL, Das S (2010) Wound healing in diabetes mellitus: traditional treatment modalities. Clin Ter 161(4):359-364

173. Diegelmann RF, Evans MC (2004) Wound healing: an overview of acute, fibrotic and delayed healing. Front Biosci 9:283-289

174. Laurens N, Koolwijk P, de Maat MPM (2006) Fibrin structure and wound healing. J Thromb Haemost 4(5):932-939

175. Wallace HA, Basehore BM, Zito PM (2019) Wound healing phases. In: StatPearls [Internet]. Treasure Island (FL): StatPearls Publishing; 2021 Jan. 2020 Sep 29.

176. Oishi Y, Manabe I (2018) Macrophages in inflammation, repair and regeneration. Int Immunol 30(11):511-528

177. Landén NX, Li D, Ståhle M (2016) Transition from inflammation to proliferation: a critical step during wound healing. Cell Mol Life Sci 73(20):3861-3885

178. Greaves NS, Ashcroft KJ, Baguneid M et al (2013) Current understanding of molecular and cellular mechanisms in fibroplasia and angiogenesis during acute wound healing. J Dermatol Sci 72(3):206-217

179. Gonzalez ACO, Costa TF, Andrade ZA et al (2016) Wound healing - a literature review. An Bras Dermatol 91(5):614-620

180. Xue M, Jackson CJ (2015) Extracellular matrix reorganization during wound healing and its impact on abnormal scarring. Adv Wound Care (New Rochelle) 4(3):119-136

181. Antonetti DA, Lieth E, Barber AJ et al (1999) Molecular mechanisms of vascular permeability in diabetic retinopathy. Semin Ophthalmol 14(4):240-248

182. Kuiper EJ, Van Nieuwenhoven FA, de Smet MD et al (2008) The angio-fibrotic switch of VEGF and CTGF in proliferative diabetic retinopathy. PLoS One. 3(7):e2675

183. Hodge S, Matthews G, Mukaro V et al (2011) Cigarette smokeinduced changes to alveolar macrophage phenotype and function are improved by treatment with procysteine. Am J Respir Cell Mol Biol 44(5):673-681

184. Mahdavian Delavary B, van der Veer WM, van Egmond $M$ et al (2011) Macrophages in skin injury and repair. Immunobiology 216(7):753-762
185. Leal EC, Carvalho E, Tellechea A et al (2015) Substance P promotes wound healing in diabetes by modulating inflammation and macrophage phenotype. Am J Pathol 185(6):1638-1648

186. Phipps KD, Gebremeskel S, Gillis J et al (2015) Alternatively activated M2 macrophages improve autologous fat graft survival in a mouse model through induction of angiogenesis. Plast Reconstr Surg 135(1):140-149

187. Yang Y, Liu F, Tang M et al (2016) Macrophage polarization in experimental and clinical choroidal neovascularization. Sci Rep 6:30933

188. Wang L, Zhang Y, Zhang N et al (2019) Potential role of M2 macrophage polarization in ventilator-induced lung fibrosis. Int Immunopharmacol. 75:105795

189. Furukawa S, Moriyama M, Tanaka A et al (2015) Preferential M2 macrophages contribute to fibrosis in IgG4-related dacryoadenitis and sialoadenitis, so-called Mikulicz's disease. Clin Immunol 156(1):9-18

190. Omri S, Behar-Cohen F, de Kozak Y et al (2011) Microglia/ macrophages migrate through retinal epithelium barrier by a transcellular route in diabetic retinopathy: role of $\mathrm{PKC} \zeta$ in the Goto Kakizaki rat model. Am J Pathol 179(2):942-953

191. Arroba AI, Alcalde-Estevez E, García-Ramírez M et al (1862) (2016) Modulation of microglia polarization dynamics during diabetic retinopathy in $\mathrm{db} / \mathrm{db}$ mice. Biochim Biophys Acta 9:1663-1674

192. Kobayashi Y, Yoshida S, Nakama T et al (2015) Overexpression of CD163 in vitreous and fibrovascular membranes of patients with proliferative diabetic retinopathy: possible involvement of periostin. Br J Ophthalmol 99(4):451-456

193. Abu El-Asrar AM, Ahmad A et al (2020) Interleukin-11 overexpression and M2 macrophage density are associated with angiogenic activity in proliferative diabetic retinopathy. Ocul Immunol Inflamm 28(4):575-588

194. Arango Duque G, Descoteaux A (2014) Macrophage cytokines: involvement in immunity and infectious diseases. Front Immunol 5:491

195. Jin X, Yao T, Zhou Z, et al (2015) Advanced glycation end products enhance macrophages polarization into M1 phenotype through activating RAGE/NF- $\mathrm{KB}$ pathway. Biomed Res Int. 2015:732450.

196. Shapouri-Moghaddam A, Mohammadian S, Vazini H et al (2018) Macrophage plasticity, polarization, and function in health and disease. J Cell Physiol 233(9):6425-6440

197. Hao S, Meng J, Zhang Y et al (2017) Macrophage phenotypic mechanomodulation of enhancing bone regeneration by superparamagnetic scaffold upon magnetization. Biomaterials 140:16-25

198. He R, Yin H, Yuan B et al (2017) IL-33 improves wound healing through enhanced M2 macrophage polarization in diabetic mice. Mol Immunol 90:42-49

199. Rao Z, Pace S, Jordan PM et al (2019) Vacuolar $\left(\mathrm{H}^{+}\right)$-ATPase critically regulates specialized proresolving mediator pathways in human M2-like monocyte-derived macrophages and has a crucial role in resolution of inflammation. J Immunol 203(4):1031-1043

200. López-Vicario C, Rius B, Alcaraz-Quiles J et al (2016) Proresolving mediators produced from EPA and DHA: overview of the pathways involved and their mechanisms in metabolic syndrome and related liver diseases. Eur J Pharmacol 785:133-143

201. Cañedo-Dorantes L, Cañedo-Ayala M (2019) Skin acute wound healing: a comprehensive review. Int J Inflam 2019:3706315

202. Kanneganti TD (2015) The inflammasome: firing up innate immunity. Immunol Rev 265(1):1-5

203. Cowie AM, Dittel BN, Stucky CL (2019) A novel sex-dependent target for the treatment of postoperative pain: the NLRP3 inflammasome. Front neurol 12(10):622 
204. Chiang N, Barnaeva E, Hu X et al (2019) Identification of chemotype agonists for human resolvin D1 receptor DRV1 with proresolving functions. Cell Chem Biol 26(2):244-254.e4

205. Barnig C, Levy BD (2015) Innate immunity is a key factor for the resolution of inflammation in asthma. Eur Respir Rev 24(135):141-153

206. Zhang Z, Hu X, Qi X et al (2018) Resolvin D1 promotes corneal epithelial wound healing and restoration of mechanical sensation in diabetic mice. Mol Vis 24:274-285

207. Kakazu A, He J, Kenchegowda S et al (2012) Lipoxin A4 inhibits platelet-activating factor inflammatory response and stimulates corneal wound healing of injuries that compromise the stroma. Exp Eye Res 103:9-16

208. Shi H, Carion TW, Jiang Y et al (2017) A regulatory role for $\beta$-adrenergic receptors regarding the resolvin D1 (RvD1) pathway in the diabetic retina. PLoS One. 12(11):e0185383

209. Shi H, Carion TW, Jiang Y et al (2016) VIP protects human retinal microvascular endothelial cells against high glucose-induced increases in TNF- $\alpha$ and enhances RvD1. Prostaglandins Other Lipid Mediat 123:28-32

210. Gundala NKV, Naidu VGM, Das UN (2018) Amelioration of streptozotocin-induced type 2 diabetes mellitus in Wistar rats by arachidonic acid. Biochem Biophys Res Commun 496(1):105-113

211. Kaviarasan K, Jithu M, Arif Mulla M et al (2015) Low blood and vitreal BDNF, LXA4 and altered Th1/Th2 cytokine balance are potential risk factors for diabetic retinopathy. Metabolism 64(9):958-966

212. Motwani MP, Colas RA, George MJ, et al (2018) Pro-resolving mediators promote resolution in a human skin model of UVkilled Escherichia coli-driven acute inflammation. JCI Insight. $3(6)$

213. Jackson JR, Seed MP, Kircher CH et al (1997) The codependence of angiogenesis and chronic inflammation. FASEB $\mathrm{J}$ 11(6):457-465

214. Lawrance IC, Wu F, Leite AZ et al (2003) A murine model of chronic inflammation- induced intestinal fibrosis down-regulated by antisense NF-kappa B. Gastroenterology 125(6):1750-1761

215. Ellis S, Lin EJ, Tartar D (2018) Immunology of wound healing. Curr Dermatol Rep 7(4):350-358

216. Fernandez-Boyanapalli R, Goleva E, Kolakowski C, et al (2013) Obesity impairs apoptotic cell clearance in asthma. J Allergy Clin Immunol. 131(4): 1041-1047, 1047.e1-3.

217. Chang HY, Lee HN, Kim W et al (2015) Docosahexaenoic acid induces M2 macrophage polarization through peroxisome proliferator-activated receptor $\gamma$ activation. Life Sci 120:39-47

218. Lai YS, Putra RBDS, Aui SP et al (2018) M2 $2_{C}$ polarization by baicalin enhances efferocytosis via upregulation of MERTK receptor. Am J Chin Med 46(8):1899-1914

219. Suresh Babu S, Thandavarayan RA, Joladarashi D et al (2016) MicroRNA-126 overexpression rescues diabetes-induced impairment in efferocytosis of apoptotic cardiomyocytes. Sci Rep 6:36207

220. Khanna S, Biswas S, Shang Y et al (2010) Macrophage dysfunction impairs resolution of inflammation in the wounds of diabetic mice. PLoS One. 5(3):e9539

221. Feenstra DJ, Yego EC, Mohr S (2013) Modes of retinal cell death in diabetic retinopathy. J Clin Exp Ophthalmol 4(5):298

222. Vandivier RW, Richens TR, Horstmann SA et al (2009) Dysfunctional cystic fibrosis transmembrane conductance regulator inhibits phagocytosis of apoptotic cells with proinflammatory consequences. Am J Physiol Lung Cell Mol Physiol 297(4):L677-686

223. Gerlach BD, Marinello M, Heinz J et al (2020) Resolvin D1 promotes the targeting and clearance of necroptotic cells. Cell Death Differ 27(2):525-539
224. Gallo PM, Gallucci S (2013) The dendritic cell response to classic, emerging, and homeostatic danger signals. Implications for autoimmunity Front Immunol 4:138

225. Ong SP, Lee LM, Leong YF et al (2012) Dengue virus infection mediates HMGB1 release from monocytes involving PCAF acetylase complex and induces vascular leakage in endothelial cells. PLoS One. 7(7):e41932

226. Fujiok S, Karashima K, Saito Y (2009) Evaluation of nonproliferative diabetic retinopathy with subgroups classified by orbital color doppler imaging. Nippon Ganka Gakkai Zasshi 113(2):95-100

227. Kaminogawa S (1996) Food allergy, oral tolerance and immunomodulation-their molecular and cellular mechanisms. Biosci Biotechnol Biochem 60(11):1749-1756

228. Komada T, Muruve DA (2019) The role of inflammasomes in kidney disease. Nat Rev Nephrol 15(8):501-520

229. Börgeson E, Sharma K (2013) Obesity, immunomodulation and chronic kidney disease. Curr Opin Pharmacol 13(4):618-624

230. Hjorth E, Freund-Levi Y (2012) Immunomodulation of microglia by docosahexaenoic acid and eicosapentaenoic acid. Curr Opin Clin Nutr Metab Care 15(2):134-143

231. Weiner HL (1997) Oral tolerance for the treatment of autoimmune diseases. Annu Rev Med 48:341-351

232. Weiner HL, da Cunha AP, Quintana F et al (2011) Oral tolerance. Immunol Rev 241(1):241-259

233. Zhang Y, Lu X, Hu Z et al (2017) Protection of Mcc950 against high-glucose-induced human retinal endothelial cell dysfunction. Cell Death Dis. 8(7):e2941

234. Trotta MC, Maisto R, Guida F et al (2019) The activation of retinal HCA2 receptors by systemic beta-hydroxybutyrate inhibits diabetic retinal damage through reduction of endoplasmic reticulum stress and the NLRP3 inflammasome. PLoS One. 14(1):e0211005

235. Isaji M, Miyata H, Ajisawa $Y$ et al (1997) Tranilast inhibits the proliferation, chemotaxis and tube formation of human microvascular endothelial cells in vitro and angiogenesis in vivo. $\mathrm{Br}$ J Pharmacol 122(6):1061-1066

236. Shen HH, Yang YX, Meng X et al (2018) NLRP3: a promising therapeutic target for autoimmune diseases. Autoimmun Rev 17(7):694-702

237. Perera AP, Fernando R, Shinde T et al (2018) MCC950, a specific small molecule inhibitor of NLRP3 inflammasome attenuates colonic inflammation in spontaneous colitis mice. Sci Rep 8(1):8618

238. Huang Y, Jiang H,Chen Y, et.al (2018) Tranilast directly targets NLRP3 to treat I inflammasome-driven diseases. EMBO Mol Med. 10(4)

239. Yin Y, Chen F, Wang W et al (2018) Resolvin D1 inhibits inflammatory response in STZ-induced diabetic retinopathy rats: Possible involvement of NLRP3 inflammasome and NF- $\kappa B$ signaling pathway. Exp Ther Med 16(4):3603-3610

240. Das UN (2010) Is lipoxins A4 a better alternative to anti-TNFalpha antibody to prevent and treat diabetic macular edema and retinopathy? Med Sci Monit. 16(9): LE13-4.

241. Das UN (2013) Lipoxins, resolvins, and protectins in the prevention and treatment of diabetic macular edema and retinopathy. Nutrition 29(1):1-7

242. Behl T, Kotwani A (2017) Omega-3 fatty acids in prevention of diabetic retinopathy. J Pharm Pharmacol 69(8):946-954

243. Yorek MS, Coppey LJ, Shevalye H et al (2016) Effect of treatment with salsalate, menhaden oil, or resolvin D1 of C57B1/6 J Type 1 diabetic mouse on neuropathic endpoints. J Nutr Metab 2016:5905891

244. Orr SK, Colas RA, Dalli J et al (2015) Proresolving actions of a new resolvin D1 analog mimetic qualifies as an immunoresolvent. Am J Physiol Lung Cell Mol Physiol 308(9):L904-911 
245. Maddox JF, Hachicha M, Takano T et al (1997) Lipoxin A4 stable analogs are potent mimetics that stimulate human monocytes and THP-1 cells via a G-protein-linked lipoxin A4 receptor. J Biol Chem 272(11):6972-6978

246. Prieto P, Rosales-Mendoza CE, Terrón V et al (2015) Activation of autophagy in macrophages by pro-resolving lipid mediators. Autophagy 11(10):1729-1744

247. Okonkwo UA, DiPietro LA (2017) Diabetes and wound angiogenesis. Int J Mol Sci. 18(7)

248. Icli B, Nabzdyk CS, Lujan-Hernandez J et al (2016) Regulation of impaired angiogenesis in diabetic dermal wound healing by microRNA-26a. J Mol Cell Cardiol 91:151-159

249. Romero-Cerecero O, Zamilpa A, Díaz-García ER et al (2014) Pharmacological effect of Ageratina pichinchensis on wound healing in diabetic rats and genotoxicity evaluation. J Ethnopharmacol 156:222-227

250. Zhang X, Yan X, Cheng L et al (2013) Wound healing improvement with PHD-2 silenced fibroblasts in diabetic mice. PLoS One. 8(12):e84548

251. London A, Benhar I, Schwartz M (2013) The retina as a window to the brain-fromeye research to CNS disorders. Nat Rev Neurol 9(1):44-53

252. Aoki N (1975) Epidemiological evaluation of funduscopic findings in cerebrovascular diseases II A multivariate analysis of funduscopic findings. Jpn Circ J. 39(3):271-282

253. Guo X, Xue H, Shao Q et al (2016) Hypoxia promotes gliomaassociated macrophage infiltration via periostin and subsequent M2 polarization by upregulating TGF-beta and M-CSFR. Oncotarget 7(49):80521-80542

254. Liu J, Qiu P, Qin J et al (2020) Allogeneic adipose-derived stem cells promote ischemic muscle repair by inducing M2 macrophage polarization via the HIF- $1 \alpha /$ IL-10 pathway. Stem Cells 38(10): 1307-1320

255. Lundberg K, Venables PJ (2008) Epitope spreading in animal models: array of hope in rheumatoid arthritis and multiple sclerosis. Arthritis Res Ther 10(6):122
256. Shen Y, Yang T, Guo S, et al (2013) Increased serum ox-LDL levels correlated with lung function, inflammation, and oxidative stress in COPD. Mediators Inflamm. 972347.

257. Kaplan M, Shur A, Tendler Y (2018) M1 macrophages but not m2 Macrophages are characterized by upregulation of CRP expression via activation of NFkappaB: a possible role for oxLDL in macrophage polarization. Inflammation 41(4):1477-1487

258. Yi X, Zhang J, Zhuang R et al (2018) Silencing LAIR-1 in human THP-1 macrophage increases foam cell formation by modulating PPARgamma and M2 polarization. Cytokine 111:194-205

259. Seo JW, Yang EJ, Yoo KH, et al (2015) Macrophage differentiation from monocytes is influenced by the lipid oxidation degree of low density lipoprotein Mediators Inflamm. 2015:235797

260. Hirose K, Iwabuchi K, Shimada K et al (2011) Different responses to oxidized low-density lipoproteins in human polarized macrophages. Lipids Health Dis 4(10): 1

261. Bostjan C, Oehler R (2020) The role of neutrophil death in chronic inflammation and cancer. Cell Death Discov 22(6):26

262. Mohammad G, Siddiquei MM, Othman A et al (2013) Highmobility group box-1 protein activates inflammatory signaling pathway components and disrupts retinal vascular-barrier in the diabetic retina. Exp Eye Res 107:101-109

263. Cooke TD, Sumia M, Elliott S et al (1983) Immune complex mediated destruction of cartilage in antigen-induced arthritis of rabbits. J Rheumatol Suppl 11:103-107

Publisher's note Springer Nature remains neutral with regard to jurisdictional claims in published maps and institutional affiliations. 